\title{
Choice of ACE inhibitor combinations in hypertensive patients with type 2 diabetes: update after recent clinical trials
}

This article was published in the following Dove Press journal:

Vascular Health and Risk Management

7 May 2009

Number of times this article has been viewed

\author{
Gianpaolo Reboldi' \\ Giorgio Gentile' \\ Fabio Angeli ${ }^{2}$ \\ Paolo Verdecchia ${ }^{2}$ \\ 'Department of Internal Medicine. \\ University of Perugia, Italy; \\ ${ }^{2}$ Department of Cardiology, Clinical \\ Research Unit 'Preventive Cardiology' \\ Hospital 'Santa Maria della \\ Misericordia', Perugia, Italy
}

\begin{abstract}
The diabetes epidemic continues to grow unabated, with a staggering toll in micro- and macrovascular complications, disability, and death. Diabetes causes a two- to fourfold increase in the risk of cardiovascular disease, and represents the first cause of dialysis treatment both in the UK and the US. Concomitant hypertension doubles total mortality and stroke risk, triples the risk of coronary heart disease and significantly hastens the progression of microvascular complications, including diabetic nephropathy. Therefore, blood pressure reduction is of particular importance in preventing cardiovascular and renal outcomes. Successful antihypertensive treatment will often require a combination therapy, either with separate drugs or with fixed-dose combinations. Angiotensin converting enzyme (ACE) inhibitor plus diuretic combination therapy improves blood pressure control, counterbalances renin-angiotensin system activation due to diuretic therapy and reduces the risk of electrolyte alterations, obtaining at the same time synergistic antiproteinuric effects. ACE inhibitor plus calcium channel blocker provides a significant additive effect on blood pressure reduction, may have favorable metabolic effects and synergistically reduce proteinuria and the rate of decline in glomerular filtration rate, as evidenced by the GUARD trial. Finally, the recently published ACCOMPLISH trial showed that an ACE inhibitor/calcium channel blocker combination may be particularly useful in reducing cardiovascular outcomes in high-risk patients. The present review will focus on different ACE inhibitor combinations in the treatment of patients with type 2 diabetes mellitus and hypertension, in the light of recent clinical trials, including GUARD and ACCOMPLISH.
\end{abstract}

Keywords: type 2 diabetes, blood pressure, ACE inhibitor

\section{Introduction}

The diabetes epidemic continues to grow. ${ }^{1}$ In the year 2000, there were an estimated 171 million patients worldwide with a diagnosed diabetes, and this number is projected to rise to 366 million in $2030,{ }^{2} 90 \%$ of whom will have a type 2 diabetes. At the time of diagnosis, about $50 \%$ of type 2 diabetics are also hypertensives. This percentage increases even more in the presence of micro- or macroalbuminuria. ${ }^{3}$ Microalbuminuria (urinary albumin excretion of 20 to $200 \mu \mathrm{g} / \mathrm{min}$ or 30 to $299 \mathrm{mg} / 24$ hours), which often heralds the onset of diabetic nephropathy, independently predicts cardiovascular morbidity and mortality in diabetic patients. ${ }^{4-6}$

Blood pressure $(\mathrm{BP})$ reduction is a major priority in preventing clinical events in patients with type 2 diabetes mellitus and hypertension, who are at very high risk of cardiovascular and renal outcomes. Diabetes causes a two- to fourfold increase in the risk of cardiovascular disease, ${ }^{7,8}$ including stroke, ${ }^{9}$ atrial fibrillation, flutter, coronary heart disease (CHD) and left ventricular hypertrophy, ${ }^{10}$ and it is the first cause of renal
Correspondence: Gianpaolo Reboldi Department of Internal Medicine, University of Perugia, 06126 - Perugia, Italy Email paolo@unipg.it 
replacement therapy both in the $\mathrm{UK}^{11}$ and the US, ${ }^{12}$ where over $40 \%$ of dialyzed patients are diabetics. Concomitant hypertension doubles total mortality and stroke risk, triples the already high risk of CHD and significantly hastens the progression of diabetic nephropathy, ${ }^{13}$ retinopathy ${ }^{14}$ and neuropathy. ${ }^{15}$ In such patients, a difference of $5 \mathrm{mmHg}$ in either systolic blood pressure (SBP) or diastolic blood pressure (DBP) increases the risk of cardiovascular events or death by $20 \%$ to $30 \% .{ }^{16}$ As a consequence, the Joint National Committee on the Prevention, Detection, Evaluation and Treatment of High Blood Pressure, ${ }^{17}$ the European Society of Hypertension $^{6}$ and the American Diabetes Association ${ }^{18}$ all recommend achieving a target of $<130 / 80 \mathrm{mmHg}$ in subjects with diabetes and hypertension.

Successful treatment of these patients will often require a combination therapy, ${ }^{19}$ either with separate drugs or with fixed-dose combinations.

Both of these offer several advantages: first, they allow a tighter BP control, and consequently a greater reduction of clinical endpoints, minimizing at the same time the risk of adverse effects, by using relatively small doses of two drugs in combination or by selecting agents that counteract each other's side effects. ${ }^{20}$ As showed by an extensive analysis of 354 randomized trials of the five main categories of BP lowering drugs, ${ }^{21}$ antihypertensive efficacy of drugs in combination was additive, but prevalence of adverse effects was less than additive. In 66 trial arms, single drugs caused symptoms in $5.2 \%$ of participants $(3.6 \%-6.6 \%)$, while in 33 trial arms two drugs together caused symptoms in $7.5 \%$ $(5.8 \%-9.3 \%)$, which is significantly lower than the value of $10.4 \%$ (twice $5.2 \%$ ) expected with an additive effect $(\mathrm{p}=0.03)$.

Secondly, in many cases less time is required to achieve target $\mathrm{BP}$, with equivalent ${ }^{22}$ or better ${ }^{23}$ tolerability than higher dose monotherapy. Finally, patients with comorbidities, such as type 2 diabetes and hypertension, may benefit from the effects of different antihypertensive combinations, that may offer specific cardio-, vasculo- and renoprotective advantages that go beyond BP reduction per se.

Fixed-dose combination therapy simplifies the treatment regimen, improving compliance and preventing treatment failures caused by missed doses. ${ }^{24}$ Moreover, it usually allows cost reductions to the health care system. ${ }^{23}$ On the other hand, it is not always possible to achieve the same medications and dosages in a combined pill, fixed-dose combinations do not allow easy dose adjustment, ${ }^{25}$ exposing patients to the risk of orthostatic hypotension (ie, older patients, diabetic autonomic neuropathy), and tablet size is sometimes excessive. ${ }^{26}$
Combination therapy with separate drugs makes it easy to obtain the desired dose, and adjust it when needed. However, potential disadvantages include patient's perception that taking more medications is equated with being sicker, ${ }^{25}$ and generally increased costs.

In hypertensive type 2 diabetics, commonly used combination therapies include an angiotensin converting enzyme (ACE) inhibitor or an angiotensin receptor blocker (ARB) plus a diuretic or a calcium channel blocker (CCB). In the present review, we will focus on two combinations:

1. ACE inhibitor plus diuretic

2. ACE inhibitor plus $\mathrm{CCB}$

\section{ACE inhibitor plus diuretic Rationale of the combination}

ACE inhibitors were able to decrease cardiovascular morbidity and mortality in the diabetic cohort of a number of trials, including the Heart Outcomes Prevention Evaluation Trial, ${ }^{27}$ the Captopril Prevention Project Trial (CAPPP),${ }^{28}$ the Fosinopril versus Amlodipine Cardiovascular Events randomized Trial (FACET), ${ }^{29}$ the Appropriate BP Control Diabetes (ABCD) Trial $^{30}$ and the UK Prospective Diabetes Study, ${ }^{19}$ even if a meta-analysis of the Blood Pressure Lowering Treatment Trialists' Collaboration (BPLTTC) demonstrated the primary importance of BP lowering for reducing cardiovascular risk in patients with or without diabetes mellitus, independently of drug classes. ${ }^{31}$ In any case, renin-angiotensin system (RAS) blockade may delay deterioration in glomerular filtration rate (GFR) and progression of albuminuria, ${ }^{32,33}$ and the renoprotective effects of RAS blockade have been shown in a number of landmark trials in patients with type 2 diabetes mellitus; ${ }^{34-36}$ comparative data from the Diabetics Exposed to Telmisartan And EnalaprIL Trial (DETAIL) established that the ACE inhibitor enalapril and the ARB telmisartan conferred similar renoprotection in patients with hypertension and early type 2 diabetic nephropathy. ${ }^{37}$ However, RAS blockade may inhibit urinary potassium excretion, and hyperkalemia remains a clinician's major concern particularly in patients with or at risk for chronic kidney disease. ${ }^{38}$

Diuretics (usually thiazides or thiazide-like indoline diuretics such as indapamide) remain among the most effective treatments for elevated BP. ${ }^{17}$ In the aforementioned BPLTTC analysis, ${ }^{31}$ diuretics appear to reduce cardiovascular events to a degree similar to ACE inhibitors, beta-blockers or CCBs. Moreover, in 13101 adults with hypertension and type 2 diabetes, enrolled in the Antihypertensive and Lipid-Lowering Treatment to Prevent Heart Attack Trial (ALLHAT), a thiazide-type diuretic, chlorthalidone, 
decreased cardiovascular complications to an extent similar to an ACE inhibitor, lisinopril, or a CCB, amlodipine ${ }^{39}$ At low doses, thiazide diuretics usually do not cause changes in renal function, ${ }^{40}$ and they can be used when the estimated GFR is $>30 \mathrm{~mL} / \mathrm{min}$. However, diuretics may cause urinary electrolyte wasting, and consequently hyponatremia, hypokalemia and/or hypomagnesemia. In addition, diuretic-induced volume reduction may activate the renin-angiotensin system, limiting their hypotensive action, ${ }^{41,42}$ and cause pre-renal azotemia. Finally, thiazide diuretics may cause metabolic adverse effects, including hyperuricemia, hypercholesterolemia and glucose intolerance, increasing a patient's likelikood of developing diabetes and worsening glycemic control in diabetic patients. ${ }^{43,44}$ About $50 \%$ of the hyperglycemic effects of thiazides is thought to be the result of decreased insulin release from the pancreatic $\beta$-cell, mediated by the reduction in serum potassium below $3.5 \mathrm{mEq} / \mathrm{L} .{ }^{45} \mathrm{In}$ fact, total body potassium stores play a central role in the control of insulin secretion, ${ }^{46}$ probably because ATP-sensitive $\mathrm{K}^{+}$ channels couple $\beta$-cell metabolism to electrical activity. A recent analysis of the Systolic Hypertension in Elderly Program (SHEP $)^{47}$ showed that incidence of new diabetes is related to the severity of hypokalemia, even after adjusting for baseline glucose and the dose of diuretic. The absolute increase in the incidence of diabetes mellitus was much less when serum potassium concentration dropped from 5.0 to $4.5 \mathrm{mEq} / \mathrm{L}$ but much higher when serum potassium dropped from 4.0 to $3.5 \mathrm{mEq} / \mathrm{L}$. In any case, it has to be noted that even when there were no changes in kalemia the incidence of diabetes was about double with placebo than with thiazide, and that $\mathrm{K}^{+}$supplementation in SHEP did not prevent newonset diabetes. In the recently published Mechanisms for the Diabetes Preventing Effect of Candesartan (MEDICA) trial, ${ }^{48}$ a multicenter 3-way crossover trial, 26 non-diabetic, obese hypertensives underwent 12 -week treatment periods with candesartan, hydrochlorothiazide (HCTZ) and placebo; after 12 weeks on thiazides (compared to candesartan), visceral and hepatic fat accumulation, higher inflammation markers (C-reactive protein, serum amyloid), glycated hemoglobin and transaminases were observed; in addition, insulin sensitivity was reduced after HCTZ versus candesartan or placebo, independently of changes in kalemia. As a consequence, the diabetogenic effects of thiazides are most likely multifactorial, with a clear non- $\mathrm{K}^{+}$dependent component. ${ }^{49}$

Therefore, the combination of an ACE inhibitor with a diuretic has a strong physiopathological rationale (Table 1); it allows improved BP control, ${ }^{50-53}$ it counterbalances RAS activation secondary to diuretic therapy and reduces the
Table I Advantages of ACE inhibitor/diuretic combination therapy Improved blood pressure control

Counterbalances renin-angiotensin system activation secondary to diuretic therapy

Reduced risk of electrolyte disorders (eg, hyper- or hypokalemia, hypomagnesemia)

Synergistic antiproteinuric effects, particularly in the presence of high sodium intake

Better therapeutic response in African-American patients

Blunts the adverse metabolic effects induced by the diuretic

risk of hyper- or hypokalemia, obtaining at the same time synergistic antiproteinuric effects. ${ }^{54}$ Additionally, high sodium intake generally blunts the antiproteinuric effects of RAS blockers; the use of thiazide diuretics overcomes this blunting effect. ${ }^{55-57}$ Moreover, the combination of an ACE inhibitor with a diuretic is particularly useful in AfricanAmerican patients, where monotherapy with conventional doses of RAS blocking agents is often unsuccessful or marginally successful. ${ }^{58}$ Finally, ACE inhibitors may at least theoretically mitigate the alterations in glucose metabolism induced by diuretics. ${ }^{59}$ Numerous clinical investigations have shown that ACE inhibitors can improve insulin action on whole-body and skeletal muscle glucose disposal in insulin-resistant and hypertensive subjects, through multiple mechanisms. For example, the acute administration of captopril during a euglycemic glucose clamp caused a $25 \%$ increase in whole-body insulin sensitivity. ${ }^{60}$ After the acute administration of captopril in type 2 diabetic subjects, a decreased daily glucose profile and increased postprandial forearm blood flow were also observed. ${ }^{61}$ Even acute oral administration of the ACE inhibitor captopril at lower doses, which has no effect on $\mathrm{BP}$, was able to improve peripheral insulin-stimulated glucose disappearance in insulin-resistant individuals. ${ }^{62}$ As discussed in an extensive review, ${ }^{63}$ chronic administration of ACE inhibitors is usually associated with increased insulin sensitivity. ${ }^{64,65}$ Large intervention trials have provided evidence that ACE inhibitor monotherapy may have a positive impact on glucose metabolism. In the Heart Outcomes and Prevention Evaluation (HOPE) study, ${ }^{66} 3.6 \%$ of the patients in the ramipril group developed diabetes, compared with $5.4 \%$ in the placebo group $(\mathrm{p}<0.001)$. In the FACET, ${ }^{29}$ both fosinopril and amlodipine decreased fasting serum glucose and serum insulin in patients with type 2 diabetes mellitus and hypertension. In the ALLHAT trial, ${ }^{67}$ only $8.1 \%$ of the patients randomized to lisinopril developed diabetes, compared with $11.6 \%$ in the diuretic group. A network meta-analysis ${ }^{68}$ showed that 
hyperglycemia and subsequent diabetes occur more often in patients receiving diuretics (or beta-blockers) instead of ACE inhibitors (or ARBs). However, only a limited number of studies has explored the metabolic effects of ACE inhibitor/ diuretic combination therapy. In 1983, two multicenter trials compared the effects of an ACE inhibitor, captopril, combined with a diuretic to the administration of either agent alone in mild to moderate hypertensives. ${ }^{69}$ In addition to BP, effects on serum potassium, uric acid, glucose, and cholesterol were examined. The first study (study A) was conducted on 210 hypertensives randomly assigned to receive HCTZ $15 \mathrm{mg} 3$ times daily, captopril $25 \mathrm{mg} 3$ times daily or captopril plus HCTZ for 6 weeks. The second study (study B) involved 415 patients randomly assigned to receive captopril $25 \mathrm{mg}$ twice daily plus HCTZ $25 \mathrm{mg}$ twice daily, captopril $50 \mathrm{mg}$ twice daily plus HCTZ $25 \mathrm{mg}$ twice daily, captopril $50 \mathrm{mg}$ twice daily plus placebo, HCTZ 25 mg twice daily plus placebo, or placebo alone for 6 weeks. In both studies, all patients except those receiving placebo only had significant BP reductions ( $p<0.05)$. In both studies, those treated with HCTZ alone had a significant $(\mathrm{p}<0.05)$ reduction in serum potassium and increases in uric acid, glucose and cholesterol when compared to captopril alone, where no significant changes in these parameters were observed in the combination arms. In another study, ${ }^{58}$ 255 essential hypertensive patients were assigned to receive HCTZ, captopril, or both. With HCTZ alone, significant decreases in serum potassium, increases in uric acid, blood glucose, and blood cholesterol were observed ( $\mathrm{p}<0.05$ ). With captopril alone, no changes in any of these parameters were seen. When captopril was added to HCTZ, attenuation of the diuretic effect on potassium and uric acid was significant, and the significant changes in blood sugar and cholesterol seen with the diuretic alone were prevented. In a small trial, ${ }^{70}$ 10 hypertensive patients with type 2 diabetes mellitus were treated for 8 weeks with enalapril $20 \mathrm{mg} /$ day and then divided in 2 groups of 5 patients each for an additional 8 weeks of treatment with enalapril alone or in combination with HCTZ; no significant difference was observed in any of the metabolic characteristics, including insulin sensitivity, between the values after 8 weeks of enalapril alone and the final values of the enalapril-treated and the enalapril/HCTZ-treated groups. In a 12-week multi-center dose-response study in 353 patients with essential hypertension, ${ }^{71}$ combination therapy with zofenopril/HCTZ (30/12.5 mg/day or 60/12.5 mg/day) was more effective in maintaining continuous 24-hour BP control than either agent administered alone; the occurrence of treatment-related adverse events was comparable among the treatment groups, and the most common adverse events were cough and polyuria. Treatment withdrawal occurred in only $1.7 \%$ of patients. There were no increases in low-density lipoprotein cholesterol levels or triglycerides, blood glucose or uric acid levels with combination therapy. However, concerns about the metabolic effects of ACE inhibitor/ diuretic combination therapy in hypertensive type 2 diabetics have been raised by other trials, ${ }^{72,73}$ even if a recent large randomized trial, ADVANCE, did not show any deterioration in glycemic control in type 2 diabetics randomized to an ACE inhibitor, perindopril, plus a thiazide-like diuretic, indapamide. ${ }^{74}$ In any case, while the metabolic effects of ACE inhibitor plus diuretic combinations are still a matter of debate, available evidence strongly supports the metabolic benefits of the ACE inhibitor/CCB combination, particularly in patients with prediabetes (glucose intolerance, metabolic syndrome or history of gestational diabetes) or diabetes mellitus (see below).

Although ACE inhibitors and diuretics have been individually used in a large number of trials on cardiovascular or renal endpoints, head-to-head comparisons between ACE inhibitor/diuretic combinations and other drugs or placebo in hypertensive type 2 diabetics are still a rarity.

\section{Cardiovascular endpoints}

In the Preterax in Albuminuria Regression (PREMIER) trial, ${ }^{75}$ which enrolled 457 microalbuminuric, hypertensive, type 2 diabetics (see below), analysis of serious cardiovascular adverse events showed an incidence of $2.5 \%$ (6 of 244) in the perindopril/indapamide group versus $6.3 \%$ (15 of 237) in the enalapril group (relative risk [RR] $2.65,95 \%$ confidence interval $[\mathrm{CI}] 1.03-6.83, \mathrm{p}=0.036)$. Combination therapy allowed a greater SBP $(-14.8 \mathrm{mmHg})$ and DBP (-8.8) reduction, as compared to enalapril monotherapy (SBP -12.3 mmHg, DBP -7.3 mmHg).

In the Perindopril Protection Against Recurrent Stroke Study, ${ }^{76}$ a total of 6105 patients with a history of stroke or transient ischemic attack were randomized to either perindopril with the discretional addition of the diuretic indapamide or placebo. $58 \%$ of participants received a combination therapy, in order to maximize the decrease in BP. The aim of the trial was to determine the effects of active treatment on major CV events among patients with a history of cerebrovascular disease. Of 6105 randomized participants, 761 had diabetes at baseline (88\% type 2 diabetes), ${ }^{77}$ with a mean SBP of $149 \mathrm{mmHg}$ and a mean DBP of $84 \mathrm{mmHg}$. During the 4 years of follow-up, diabetic patients had a $35 \%$ (95\% CI 10-64, p = 0.004) additional risk of stroke. 
The RR estimates for total major vascular events among diabetic participants were 0.54 (95\% CI 0.35-0.82) and 1.35 $(95 \%$ CI $0.87-2.1)$ ( $\mathrm{p}$ homogeneity $=0.003$ ) for patients assigned at baseline to receive combination (perindopril plus indapamide) and single-drug therapy, respectively. Likely, the greater BP reduction produced by combination therapy may explain part of the protection against macrovascular events.

The Action in Diabetes and Vascular Disease: preterAx and diamicroN-MR Controlled Evaluation (ADVANCE) study ${ }^{74}$ was designed to assess the effects on vascular disease of a fixed combination of the ACE inhibitor perindopril and the diuretic indapamide. In this study, 11,140 patients with type 2 diabetes, at least one additional risk factor and a wide range of BP values (mean baseline SBP: $145 \mathrm{mmHg}$; mean baseline DBP: $81 \mathrm{mmHg}$ ) were randomized to double-blind treatment with either perindopril-indapamide $(n=5569)$ or placebo $(n=5$ 571). Primary study outcome was a composite of major macrovascular (cardiovascular $[\mathrm{CV}]$ death, non-fatal myocardial infarction [MI], non-fatal stroke) and microvascular (new or worsening nephropathy and retinopathy) events. After a mean of 4.3 years of followup, active therapy reduced SBP by $5.6 \mathrm{mmHg}$ and DBP by $2.2 \mathrm{mmHg}$, as compared to placebo. 861 patients (15.5\%) in the perindopril/indapamide group and 938 (16.8\%) in the placebo group reached the primary outcome (relative risk reduction: $9 \% ; 95 \% \mathrm{CI} 0 \%-17 \% ; \mathrm{p}=0.041)$. The effects of active treatment on major macro- or microvascular outcomes were similar ( $8 \%$ vs $9 \%$ ), though not separately significant. The RR of death from CV disease was reduced by $18 \%$ $(\mathrm{p}=0.03)$ and death from any cause by $14 \%(\mathrm{p}=0.03)$. There was no evidence of an interaction between the effect of treatment and baseline SBP, considered as a continuous variable.

\section{Renal endpoints}

In an old trial comparing the long-term effects of ACE inhibitors and CCBs in the treatment of type 2 diabetes associated with hypertension, ${ }^{78} 102$ patients normo- $(n=44)$, micro- $(n=36)$ or macroalbuminuric $(n=22)$ were randomly allocated to either nifedipine $(n=52)$ or enalapril $(n=50)$. Indapamide $2.5 \mathrm{mg}$ /day or furosemide (up to $120 \mathrm{mg} /$ day) were added if the BP remained high. At 1 year, $76 \%$ of the patients in the enalapril arm required the addition of diuretic treatment, as compared with only $14 \%$ in the nifedipine arm. Treatment with enalapril (and diuretic) reduced proteinuria significantly more than nifedipine, in all patients and also in the micro- and macroalbuminuric groups separately, despite a significantly higher BP in the enalapril than in the nifedipine arm of the trial $(p<0.001)$.

The Preterax in Albuminuria Regression (PREMIER) trial $^{75}$ was designed as a 12-month, randomized, controlled, double-blind, two-parallel group study. 457 patients with type 2 diabetes, hypertension and microalbuminuria were randomized to either low-dose combination of perindopril and indapamide $(n=233)$ or enalapril monotherapy $(n=224)$. Primary endpoint was the reduction of albumin excretion rate (AER). The perindopril/indapamide combination resulted in a statistically significant reduction in both $\mathrm{BP}(\triangle \mathrm{SBP}-3.05$ $\mathrm{mmHg}, 95 \% \mathrm{CI}-5.6 /-0.4, \mathrm{p}=0.012 ; \Delta \mathrm{DBP}-1.5 \mathrm{mmHg}$, 95\% CI: $-3 /-0.1, \mathrm{p}=0.019)$ and AER $(-42 \%, 95 \% \mathrm{CI}-50$ to $-33 \%$; versus $-27 \%, 95 \% \mathrm{CI}-37 /-16 \%$ with enalapril). Additionally, the greater AER reduction remained significant after adjustment for mean BP. Tolerability was comparable between therapies, with 47 adverse events in the combination versus 48 in the enalapril arm; the most frequent ones were cough (perindopril/indapamide 3.7\%, enapril 2.1\%) and dizziness (perindopril/indapamide $1.2 \%$, enalapril $2.1 \%$ ).

In the aforementioned ADVANCE trial, the following renal events were taken into account: development of microor macroalbuminuria, doubling of serum creatinine level to a level of at least $200 \mu \mathrm{mol} / \mathrm{L}$, need for renal replacement therapy, or death from renal disease. During the followup period there were $1243(22.3 \%)$ total renal events in the perindopril-indapamide group versus $1500(26.9 \%)$ in the placebo group, with a relative risk reduction of $21 \%$ (95 CI 15\%-7\%, p < 0.0001). A nearly significant reduction in new or worsening nephropathy was also observed (RR reduction: $18 \%$; 95\% CI -1 to $-32 \%$; $\mathrm{p}=0.055$ ). Of particular importance in the setting of primary prevention of diabetic nephropathy (ie, normoalbuminuric patients), there was a significant reduction in the onset of microalbuminuria (RR reduction: 21\%; 95\% CI 14\%-27\%; p < 0.0001). Thus, over 5 years, 1 patient in every 20 assigned active treatment would have avoided 1 renal event, mainly the development of microalbuminuria. However, the most important factors that prevent the progression of renal damage in diabetes mellitus are the improvement of blood glucose control and a tighter $\mathrm{BP}$ control. In the ADVANCE trial, a reduction of $5.6 \mathrm{mmHg}$ in SBP was observed among patients randomized to receive perindopril and indapamide, as compared with those assigned to receive placebo. Additionally, the same 11,140 patients were also randomized to undergo either a strategy of intensive blood glucose control (target glycated hemoglobin $\leq 6.5 \%$ ) or a strategy of standard glucose control, ${ }^{79}$ and intensive control reduced the incidence of combined major- or microvascular 
events by $10 \%$ (hazard ratio [HR] $0.9,95 \%$ CI $0.82-0.98$, $\mathrm{p}=0.01)$ and the incidence of nephropathy by $21 \%$ (HR $0.79,95 \%$ CI $0.66-0.93, p=0.006)$. As a consequence, the specific role of the fixed-dose combination of perindopril and indapamide in reducing the risk of new or worsening nephropathy is difficult to establish.

\section{ACE inhibitor plus CCB}

\section{Rationale of the combination}

The effects of RAS blockade in patients with type 2 diabetes and hypertension have already been described. Contrasting results have been reported on the $\mathrm{CV}$ effects of CCBs in diabetic hypertensive patients. In the Swedish Trial in Old Patients with hypertension-2 (STOP-2), 719 diabetic and hypertensive patients aged 70 to 84 years were assigned to calcium antagonists (felodipine or isradipine, $\mathrm{N}=231$ ), ACE inhibitors (enalapril or lisinopril, $\mathrm{N}=235$ ) or conventional treatment (diuretics or beta-blockers, $\mathrm{N}=253$ ). The BP-lowering effects were similar in the three treatment groups. Treatment effects did not differ significantly for frequency of the primary endpoint ( $\mathrm{CV}$ mortality). On the contrary, the ABCD trial, comparing enalapril and nisoldipine in 470 patient with non-insulin dependent diabetes and hypertension, was stopped prematurely because of a significantly higher incidence of MI among those randomized to CCB. ${ }^{30}$ In the Irbesartan versus amlodipine Diabetic Nephropathy Trial, ${ }^{35} 1715$ hypertensive patients with type 2 diabetic nephropathy were randomized to either irbesartan or amlodipine or placebo. After 2.6 years of follow-up, the treatment with $\mathrm{CCB}$, compared with $\mathrm{ARB}$, provided the same incidence of major $\mathrm{CV}$ events, $\mathrm{CV}$ death, and total mortality. Finally, the FACET trial, ${ }^{29}$ which enrolled 380 hypertensive type 2 diabetics randomly assigned to openlabel fosinopril or amlodipine and followed up for 3.5 years, found a higher incidence of the combined outcome of acute $\mathrm{MI}$, stroke, or hospitalized angina among patients assigned to amlodipine. However, those trials (STOP-2, ABCD, IDNT and FACET) are head-to-head comparisons between CCBs and agents blocking the RAS, and a few of them may suffer from a number of methodological flaws. ${ }^{81}$ In fact, CCBs compared with conventional therapy are able to reduce the risk of non-fatal stroke by $25 \%,{ }^{82}$ thanks to their antiatherogenic ${ }^{83-85}$ and antithrombotic ${ }^{86,87}$ properties. On the other hand, CCBs (mainly dihydropyridinic) could increase the risk of $\mathrm{MI},{ }^{82}$ through an increased adrenergic stimulation. Finally, dihydropyrinidic CCBs may commonly cause ankle edema, through three different mechanisms: arteriolar vasodilation, impairment of the local vascular autoregulation of blood flow and impaired protection against hydrostatic load. ${ }^{88}$ Differences in sympathetic overactivation after arterial vasodilatation may lead to different ankle edema rates. So, dihydropyridinic CCBs that activate the sympathetic nervous system to a lesser extent (ie, manidipine) ${ }^{89}$ may have a more favorable adverse event profile.

CCBs differ in their effect on glomerular hemodynamics and urinary albumin excretion..$^{90}$ Conventional dihydropyridinic CCBs may cause vasodilation of afferent renal arterioles with little change in the efferent arteriole diameter, and consequently increase intraglomerular pressure and proteinuria; newer dihydropyrinidic CCBs (ie, manidipine, benidipine) are believed to induce vasodilatation not only in the glomerular afferent arteriole, but also in the efferent arteriole, resulting in a reduced proteinuria. ${ }^{91-93}$ Non-dihydropyridinic CCBs (ie, verapamil) offer a mild protective effect on proteinuria in diabetic nephropathy, beyond their antihypertensive action. ${ }^{94}$ Concerning the renal effects of CCBs in patients with type 2 diabetes and hypertension, it is important to note that all trials directly comparing $\mathrm{CCBs}$ and RAS blocking agents (ACE inhibitors or ARBs) showed no difference in the rate of change of GFR. ${ }^{81}$ So, even if albuminuria is usually more markedly reduced by ACE inhibitors or ARBs than by $\mathrm{CCBs}$, this does not translate into a greater renoprotection, as expressed by the slope of GFR reduction, but only into greater $\mathrm{CV}$ protection.

In light of the above, the combination of an ACE inhibitor with a CCB may offer several advantages (Table 2). First, it obviously provides a consistent and significant addictive effect on BP reduction, ${ }^{95-103}$ without affecting lipid and carbohydrate metabolism. ${ }^{104}$

Secondly, ACE inhibitors plus CCBs may have favorable metabolic effects. In hypertensive patients with impaired glucose tolerance, the combination of trandolapril with verapamil

Table 2 Advantages of ACE inhibitor-calcium channel blocker combination therapy

Improved blood pressure control

Favorable metabolic effects

Counterbalances the reflex increase in sympathetic nervous activity induced by calcium channel blockers

Reduced vasodilatory edema

Diuretic and natriuretic effects of calcium channel blockers

Synergistic reduction of proteinuria and the rate of decline in glomerular filtration rate

Increased NO production and decreased cytokine production

Improved fybrinolitic balance

Improved arterial distensibility 
reduced the risk of new-onset diabetes, as compared with an angiotensin receptor blocker plus a thiazide diuretic; ${ }^{105}$ in the Anglo-Scandinavian Cardiac Outcomes Trial-Blood Pressure Lowering Arm (ASCOT-BPLA), ${ }^{106}$ an ACE inhibitor/CCB combination lowered the risk of new-onset diabetes by $30 \%$; in addition, type 2 diabetic patients treated with trandolapril plus verapamil had a better glycemic control than those treated with an ACE inhibitor as monotherapy, unrelated to their antihypertensive effect. ${ }^{107}$ The metabolic results are even better when new dihydropyridines are combined with ACE inhibitors. A recent trial showed a remarkable $59 \%$ increase in insulin sensitivity with the delapril/manidipine fixed combination in obese hypertensives after 24 weeks, while olmesartan/thiazide combination was ineffective. ${ }^{108}$ Two mechanisms have been proposed for the reduction of insulin resistance observed with CCBs: first, these drugs produce vasodilation and enhance blood flow to skeletal muscle with consequent increased delivery of insulin and glucose and enhanced non-oxidative pathways of glucose utilization; in addition, CCBs also improve insulin sensitivity at the cellular level by decreasing the cytosolic-free calcium concentrations. ${ }^{109,110}$

Thirdly, systemic vasodilation induced by $\mathrm{CCBs}$ (especially dihydropyridines) signals a reflex increase in sympathetic nervous activity, which thereby increases heart rate and enhances renal renin excretion, ${ }^{111}$ reducing the hypotensive properties of the drug; these effects may be counterbalanced by RAS blockade. Fourthly, vasodilatory edema that may occur with CCBs is often diminished when an ACE inhibitor is added to the antihypertensive regimen. ${ }^{12}$ Fifthly, the diuretic and natriuretic effect of CCBs complements ACE inhibitor therapy much as diuretic therapy does, but makes it possible to control BP without using a diuretic when that is desirable; ${ }^{113}$ additionally, ACE inhibitors blunt the stimulation of the renin-angiotensin-aldosterone axis that may result from this diuretic effect. Sixthly, in hypertensive type 2 diabetics, the combination of an ACE inhibitor and a CCB may synergistically reduce proteinuria and the rate of decline in GFR. ${ }^{114}$ Finally, ACE inhibitors and CCBs stimulate nitric oxide (NO) production through kinin-dependent mechanisms and significantly decrease levels of all inflammatory markers (tumor necrosis factor- $\alpha$, interleukin-6, nuclear factor- $\kappa \mathrm{B}$ ); preclinical evidence suggests that combination therapy has additive effects. ${ }^{115-117}$ The mechanisms of vascular damage in diabetic patients are very complex, but excess production of reactive oxygen species, endothelial dysfunction and decreased NO bioavailability play key pathogenic roles. In such patients, the neurohormonal imbalance between angiotensin II and NO associated with endothelial dysfunction may also contribute to inflammation and cardiac remodeling after myocardial ischemia. So, ACE inhibitor/CCB combination therapy may have beneficial effects in the management of cardiac ischemia and left ventricular hypertrophy, by limiting inflammation and restoring neurohormonal balance, ${ }^{118}$ as well as on fibrinolytic balance ${ }^{119}$ and arterial distensibility. ${ }^{120,121}$

A number of hypertension trials and trials on $\mathrm{CV}$ or renal endpoints have compared ACE inhibitor/CCB combination therapy and other drugs/placebo in patients with type 2 diabetes and hypertension.

\section{Hypertension trials}

In $1991,{ }^{104}$ in order to assess the efficacy and tolerability of a diuretic-free antihypertensive therapy with an ACE inhibitor and a CCB, 47 type 2 diabetic hypertensives randomly received verapamil or enalapril alone and, if BP remained elevated, both agents combined, over a 30-week period. After 10 weeks of monotherapy, 30 patients obtained a DBP lower than $90 \mathrm{mmHg}$. In the remaining 17 patients, verapamil/enalapril combination therapy decreased BP from $170 \pm 4 / 104 \pm 2$ to $152 \pm 4 / 90 \pm 2 \mathrm{mmHg}(\mathrm{p}<0.001)$. Fasting plasma glucose, glycosylated hemoglobin, serum fructosamine, total lipids, high-density and low-density lipoprotein cholesterol, apolipoproteins A-I and B, creatinine, and urinary albumin-creatinine ratio were not significantly modified, demonstrating that BP can be effectively decreased without adversely affecting carbohydrate and lipid metabolism.

A subsequent small crossover trial in 38 patients with type 2 diabetes and hypertension, ${ }^{119}$ assigned to benazepril $10 \mathrm{mg} /$ day, amlodipine $5 \mathrm{mg} /$ day or their combination, showed that combination therapy produced a significantly greater reduction in both SBP and DBP than either drug alone, with a mean decrease in BP of $-28.3 /-20.5 \mathrm{mmHg}$ ( $\mathrm{p}<0.001$ versus placebo; $\mathrm{p}<0.01$ versus benazepril or amlodipine monotherapies). The benazepril/amlodipine combination improved fybrinolytic balance more than the single drugs, due to both the decrease in plasma PAI-1 activity and the increase in t-PA activity. These effects may be of particular importance in diabetic hypertensive patients, who have an impaired fibrinolytic activity, which may contribute to the increased risk of atherosclerosis and its clinical complications.

In the Study of Hypertension and the Efficacy of Lotrel in Diabetes (SHIELD) trial, ${ }^{122}$ a randomized, double-blind study, 214 patients with hypertension and type 2 diabetes were assigned to amlodipine/benazepril (5/10 mg) combination therapy or conventional treatment (enalapril $10 \mathrm{mg} /$ day). 
If target $\mathrm{BP}(<130 / 85 \mathrm{mmHg})$ was not achieved, study drugs were titrated to $10 / 20 \mathrm{mg} /$ day or $20 \mathrm{mg} /$ day, respectively. HCTZ was added if target BP was still not reached. Time from baseline to achieve $\mathrm{BP}<130 / 85 \mathrm{mmHg}$ was shorter in the combination arm $(5.3 \pm 3.1$ weeks versus $6.4 \pm 3.8$ weeks, $\mathrm{p}=0.001$ ). At 3 months, $63 \%$ of patients in the combination group achieved treatment goal, versus $37 \%$ in the conventional treatment group $(\mathrm{p}=0.002)$.

A controlled clinical trial ${ }^{123}$ investigated the CCB lercanidipine versus HCTZ as add-on to enalapril monotherapy in diabetic patients (type 1 or 2 ) with uncontrolled hypertension. 174 subjects were included in a 2-week placebo run-in, followed by 4 weeks on enalapril $20 \mathrm{mg} /$ day. Therefore, 135 non-responders (DBP $\geq 90 \mathrm{mmHg}$ ) were randomized to either lercanidipine $10 \mathrm{mg} /$ day or HCTZ $12.5 \mathrm{mg} /$ day. Both add-on therapies reduced DBP to a greater extent than enalapril monotherapy; target BP (130/85 $\mathrm{mmHg}$ ) was achieved in $30.4 \%$ of patients on lercanidipine add-on and in $23.2 \%$ of subjects on HCTZ add-on, but the differences between the responder rates in the two treatment groups did not reach statistical significance $(\mathrm{p}>0.05)$. Both combinations were well tolerated.

The Amlodipine in Diabetes (ANDI) trial, ${ }^{124}$ a randomized parallel-group trial, investigated BP lowering in 374 patients with type 2 diabetes and hypertension. Subjects not reaching BP goals $(<130 / 80 \mathrm{mmHg})$ after a 4-week open-label treatment with quinapril $20 \mathrm{mg} /$ day $(\mathrm{n}=374)$ were assigned to either quinapril $40 \mathrm{mg} /$ day $(\mathrm{n}=167)$ or quinapril $20 \mathrm{mg} /$ day plus amlodipine $5 \mathrm{mg} /$ day $(\mathrm{n}=62)$. After 6 weeks of treatment, patients receiving combination therapy had significantly greater reductions in $\mathrm{SBP}(9.9 \pm 1.0 \mathrm{mmHg}$ vs $4.3 \pm 1.1 \mathrm{mmHg}$, $\mathrm{p}<0.001)$ and DBP $(6.5 \pm 0.6 \mathrm{mmHg}$ vs $2.7 \pm 0.6 \mathrm{mmHg}$, $\mathrm{p}<0.001$ ), as compared to quinapril monotherapy. Both treatments were well tolerated, and showed a clinically neutral effect on high-sensitivity C-reactive protein.

The MORE trial ${ }^{125}$ investigated the efficacy of the fixeddose combination of a CCB (manidipine $10 \mathrm{mg} /$ day) and an ACE inhibitor (delapril $30 \mathrm{mg} /$ day), compared with a combination of an ARB (losartan $50 \mathrm{mg}$ /day) and a diuretic (HCTZ $12.5 \mathrm{mg} /$ day), in 314 patients with hypertension and controlled type 2 diabetes $\left(\mathrm{HbA}_{1 \mathrm{c}} \leq 7.5 \%\right)$. All patients underwent ambulatory BP monitoring at baseline and at the end of treatment. After 12 weeks, mean decreases in 24-hour SBP were $-9.3 \mathrm{mmHg}$ in the manidine/delapril arm $(\mathrm{n}=80)$ and $-10.7 \mathrm{mmHg}$ in the losartan/HCTZ $\operatorname{arm}(\mathrm{n}=94)$, respectively. The mean treatment difference was $-1.4 \mathrm{mmHg}$ (95\% CI -4.5/-1.8), demonstrating the non-inferiority of the manidipine/delapril combination. A lower percentage of patients with increased HBA1c or requiring additional oral antidiabetic therapy was also observed in the CCB/ACE group. Both treatments were well tolerated and displayed comparable safety profiles.

\section{Cardiovascular endpoints}

Few large randomized clinical trials have evaluated the effects of a combination regimen (ACE inhibitor $+\mathrm{CCB}$ ) on major CV outcomes in patients with both diabetes (mostly type 2) and hypertension.

In the aforementioned FACET trial, ${ }^{29} 380$ type 2 diabetic hypertensives were assigned to open-label therapy with either fosinopril $(n=189)$ or amlodipine $(n=191)$. The goal BP was defined as $\mathrm{SBP} \leq 140 \mathrm{mmHg}$ and $\mathrm{DBP} \leq 90 \mathrm{mmHg}$. However, if BP was not controlled with monotherapy, the other study drug was added at full dose. Therefore, amlodipine was added in $30.7 \%$ of the fosinopril group patients (58/189), and fosinopril was added in $26.2 \%$ of the amlodipine group patients. The proportion of patients reaching the combined end point of stroke, acute MI or hospitalized angina was significantly lower in the fosinopril group compared with amlodipine (HR 0.49, 95\% CI 0.26-0.95, p=0.03). In crude analyses according to postrandomization treatment, the patients who received fosinopril only $(n=131)$, amlodipine only $(n=141)$ and the combination of fosinopril plus amlodipine $(n=108)$ experienced 10,27 , and 4 major vascular events, respectively. In the same three groups, the number of patients experiencing acute MI was 7, 13, and 3, respectively; the number of patients with hospitalized angina was 0, 4 and 0; and the number of patients who experienced stroke was 3, 10 and 1, respectively. Compared with amlodipine alone, the combination treatment with fosinopril and amlodipine decreased the risk of major vascular events more than fosinopril only (HR $0.17,95 \%$ CI $0.06-0.5, \mathrm{p}=0.001$ versus HR $0.37,95 \%$ CI $0.18-0.77, \mathrm{p}=0.008$, respectively). Therefore, combination therapy with ACE inhibitor and CCB scored better than monotherapy, but this important finding was not emphasized by the authors. ${ }^{81}$

In the Hypertension Optimal Treatment (HOT) trial, ${ }^{126} 18,790$ hypertensive patients (DBP between 100 and $115 \mathrm{mmHg}$ ) were randomly assigned to different target diastolic BP: $\leq 90 \mathrm{mmHg}$ $(n=6264), \leq 85 \mathrm{mmHg}(\mathrm{n}=6264)$ or $\leq 80 \mathrm{mmHg}(\mathrm{n}=6262)$. A CCB (felodipine) was given as baseline therapy, with the possible addition of other agents, according to a 5-step regimen. ACE inhibitors were added at step two, and most patients received an $\mathrm{ACE}$ inhibitor/CCB combination therapy. In the diabetic cohort of the trial $(n=1501)$, a decline in the rate of major $\mathrm{CV}$ events was observed in relation to the target 
group $(\mathrm{p}=0.005)$. In the group randomized to $\leq 80 \mathrm{mmHg}$ the risk of major $\mathrm{CV}$ events was halved in comparison with that of the target group $\leq 90 \mathrm{mmHg}$. When silent MI was included, this change was attenuated but remained significant. The approximate halving of the risk was also observed for all MI, although not statistically significant. All stroke also showed a declining rate with lower target BP groups, with a risk reduction of about $30 \%$ in the $\leq 80 \mathrm{mmHg}$ target group vs $\leq 90 \mathrm{mmHg}$ target group. Cardiovascular mortality was also significantly lower in the $\leq 80 \mathrm{mmHg}$ target group than in each of the other target groups.

In the diabetic subgroup of the Systolic Hypertension in Europe Trial (492/4695 patients), ${ }^{127}$ subjects with diabetes and systolic hypertension were randomly assigned to either active treatment or placebo. Active treatment consisted of a CCB (nitrendipine 10 to $40 \mathrm{mg} /$ day), with the possible addition or substitution of enalapril ( 5 to $20 \mathrm{mg}$ /day) or HCTZ (12.5 to $25 \mathrm{mg}$ /day) or both, titrated to reduce SBP by at least $20 \mathrm{mmHg}$ and to less than $150 \mathrm{mmHg}$. Again, the second step was an ACE inhibitor, and most patients received an ACE inhibitor plus $\mathrm{CCB}$ combination. At 2 years, active treatment reduced overall mortality by $55 \%$ (from 45.1 deaths per 1000 patients to 26.4 deaths per 1000 patients), CV mortality by $76 \%$, all CV events combined by $69 \%$, fatal and non-fatal strokes by $73 \%$ and all cardiac events combined by $63 \%$. Reductions in overall mortality, CV mortality and all CV events were significantly larger among the diabetic patients than among the nondiabetics $(p=0.04, p=0.02$, and $\mathrm{p}=0.01$, respectively).

The International Verapamil-Trandolapril Study (INVEST), ${ }^{128}$ a prospective, randomized, open-label, blinded endpoint (PROBE) trial, enrolled 22,576 patients with hypertension and CHD, randomly assigned to a nondihydropyridine CCB (verapamil SR) or a beta blockerbased (atenolol) regimen, and followed up for a mean duration of 2.7 years. In the diabetic cohort of the trial, ${ }^{129}$ 6,400 patients were randomized to $240 \mathrm{mg}$ /day of verapamil SR or $50 \mathrm{mg} /$ day of atenolol, titrated to maximal doses to achieve a target $\mathrm{BP}$ of $<130 / 85 \mathrm{mmHg}$. If $\mathrm{BP}$ goal was not achieved, trandolapril and HCTZ were recommended as primary and secondary add-on agents in the verapamil SR group, and the sequence was reversed in the atenolol group. At 24 months, the majority of participants required add-on therapy, with differences in use of trandolapril and HCTZ by strategy. In the verapamil SR group, $72.1 \%$ of patients were taking trandolapril and 51.2\% HCTZ, versus $64.1 \%$ and $62.8 \%$ of patients in the atenolol group, respectively. Risk for primary (a composite of death, non-fatal MI or non-fatal stroke) and secondary outcomes (death, non-fatal MI, non-fatal stroke, BP control, CV hospitalizations, and CV death) did not differ by strategy, as well as BP control. Finally, an on-treatment analysis of randomized drugs, using atenolol $50 \mathrm{mg} /$ day as a reference group, indicated a trend for reduced risk of the primary outcome with the addition of $2 \mathrm{mg}$ /day of trandolapril to the verapamil-SR based strategy or of $12.5 \mathrm{mg}$ /day of HCTZ to the atenolol-based strategy. This trial suggested that a combination therapy was more effective for reducing adverse outcomes in diabetic hypertensives, and that an ACE inhibitor/CCB combination could be used as an alternative to a beta-blocker based strategy in patients with concomitant CAD.

In the Bergamo Nephrologic Diabetes Complication (BENEDICT) trial, ${ }^{130}$ enrolling 1204 normoalbuminuric patients with type 2 diabetes and hypertension, randomized to trandolapril, verapamil, verapamil plus trandolapril or placebo (see below), the incidence of non-fatal CV events was similar in the four treatment groups $(3.7 \%$ in the combination group, $4.0 \%$ in the trandolapril group, $4.3 \%$ in the verapamil group, and $4.0 \%$ in the placebo group). One subject receiving trandolapril, 1 receiving verapamil, and 3 receiving placebo died from a $\mathrm{CV}$ event. No fatal $\mathrm{CV}$ events occurred in the group receiving trandolapril plus verapamil.

The Anglo-Scandinavian Cardiac Outcomes Trial-Blood Pressure Lowering Arm (ASCOT-BPLA) ${ }^{106}$ was designed to compare the effect on non-fatal MI and fatal CHD of two combination strategies, atenolol plus bendroflumethiazide versus amlodipine plus perindopril, in more than 19,000 hypertensive patients with no prior history of CHD. The study population was required to have at least three additional risk factors for CV disease: type 2 diabetes, peripheral arterial disease, previous stroke or transient ischemic attack, microalbuminuria or proteinuria, smoking and so forth. In the diabetic cohort of the trial, ${ }^{131} 5137$ patients were randomized to the atenolol-based regimen $(n=2572)$ or to the amlodipinebased regimen $(n=2565)$. A majority of patients received combination treatment with either amlodipine and perindopril or atenolol and thiazide, respectively. The mean SBP and DBP throughout the trial were 3.0 and $1.9 \mathrm{mmHg}$ lower in the amlodipine/perindopril arm. In the latter, a significantly lower incidence of total $\mathrm{CV}$ events was observed, compared with the atenolol/HCTZ regimen (HR $0.86,95 \% \mathrm{CI}$ $0.76-0.98, p=0.026)$. Fatal and non-fatal strokes were $25 \%$ lower $(p=0.017)$, peripheral arterial disease $48 \%$ lower $(p=0.004)$ and coronary revascularization procedures $57 \%$ lower $(\mathrm{p}<0.001)$ in the amlodipine/perindopril group. However, non-fatal MI and fatal CHD, the primary endpoint 
in ASCOT, were reduced by a non-significant 8\% (HR 0.92, 95\% CI 0.74-1.15, $\mathrm{p}=0.46$ ).

The recently published Avoiding Cardiovascular events through COMbination therapy in Patients Living with Systolic Hypertension (ACCOMPLISH) trial, ${ }^{132}$ which included a large population of diabetic patients (see below), indicates that the combination of an ACE inhibitor and a $\mathrm{CCB}$ was superior to the combination of an ACE inhibitor and a diuretic in reducing $\mathrm{CV}$ endpoints.

\section{Renal endpoints}

In a randomized, double-blind, parallel group designed trial, ${ }^{133} 37$ patients with type 2 diabetes, hypertension and urinary protein excretion of $>300 \mathrm{mg}$ /day were assigned to verapamil (a non-dihydropyridinic CCB), trandolapril or trandolapril + verapamil. Primary endpoint was a $25 \%$ greater reduction in urinary protein excretion (detected using 24-hour urine determinations) in the combination group as compared to either trandolapril or verapamil alone. During the trial, there was a 3 to $4 \mathrm{mmHg}$ lower mean arterial pressure in the combination group versus monotherapy groups. The combination of trandolapril and verapamil produced and sustained a greater reduction in proteinuria (from 1403 to $592 \mathrm{mg} /$ day) compared to higher doses of either verapamil (from 1349 to $985 \mathrm{mg}$ /day) or trandolapril (from 1274 to $840 \mathrm{mg} / \mathrm{day}$ ), independently of BP reduction $(\mathrm{p}<0.05)$.

In a subsequent, larger trial, ${ }^{134} 309$ hypertensive patients with type 2 diabetes and microalbuminuria were randomized to the dihydropyridinic CCB amlodipine ( 5 to $15 \mathrm{mg} /$ day), the ACE inhibitor fosinopril (10 to $30 \mathrm{mg} /$ day), or both drugs. During the 4 years of follow-up, combination therapy was more effective in reducing BP than either drug alone, without affecting glucose homeostasis. All three treatments resulted in a significant decrease in urinary albumin excretion (UAE), but this effect became evident earlier and was more pronounced in the fosinopril than in the amlodipine arm. Again, combination therapy provided a greater antialbuminuric effect than the single drugs. In addition, a greater percentage of patients in the combination group were nonmicroalbuminuric at 4 years than in amlodipine or fosinopril groups (67\%, 33\% and $46 \%$, respectively).

In a 12-week, double-blind SHIELD substudy, ${ }^{121}$ 20 patients with hypertension, type 2 diabetes and microalbuminuria were randomized to either a fixed-dose combination of amlodipine and benazapril or to enalapril monotherapy. At week 12, subjects in both the combination and the enalapril group experienced similar reductions from baseline in urinary microalbumin excretion, from $124 \pm 91 \mu \mathrm{g} / \mathrm{mg}$ to $36 \pm 14 \mu \mathrm{g} / \mathrm{mg}$ creatinine and from $102 \pm 58 \mu \mathrm{g} / \mathrm{mg}$ to $27 \pm 23 \mu \mathrm{g} / \mathrm{mg}$ creatinine, respectively $(\mathrm{p}<0.01$ for both groups). Patients in both treatment groups demonstrated similar reductions in BP.

In the specific setting of primary prevention of diabetic nephropathy, the Bergamo Nephrologic Diabetes Complication Trial (BENEDICT) ${ }^{130}$ was designed to assess whether ACE inhibitors and non-dihydropyridine CCBs, alone or in combination, are able to prevent microalbuminuria in patients with type 2 diabetes, hypertension and normal urinary albumin excretion. 1204 normoalbuminuric patients were randomized to trandolapril $(n=301)$, verapamil $(n=303)$, verapamil plus trandolapril $(n=300)$ or placebo $(n=300)$. Primary endpoint was the development of persistent microalbuminuria (overnight AER $\geq 20 \mu \mathrm{g} / \mathrm{min}$ at two consecutive visits). Target BP was 120/80 mmHg. As compared with placebo, trandolapril plus verapamil and trandolapril alone decreased the incidence of microalbuminuria to a similar extent. In particular, persistent microalbuminuria developed in $5.7 \%$ of patients receiving combination therapy, as compared with $10 \%$ of the subjects receiving placebo. In addition, the effects of trandolapril/verapamil and trandolapril in preventing microalbuminuria exceeded expectations based on BP reduction per se. On the other hand, verapamil alone did not significantly delay the onset of microalbuminuria.

In the Add-on manidipine versus amlodipine in diabetic patients with hypertension and microalbuminuria (AMANDHA) trial, ${ }^{135} 91$ diabetic patients with uncontrolled hypertension and microalbuminuria despite full-dose treatment with a renin-angiotensin system blocker were randomized to either manidipine $20 \mathrm{mg} /$ day $(\mathrm{n}=61)$ or amlodipine $10 \mathrm{mg} /$ day $(\mathrm{n}=30)$ in a $2: 1$ ratio. After 6 months of treatment, patients were monitored for microalbuminuria for additional 18 months. Urinary albumin excretion was reduced by $65.5 \%$ with manidipine versus $20 \%$ with amlodipine at 6 months $(\mathrm{p}<0.01)$, and by 62.7 versus $16.6 \%(\mathrm{p}<0.01)$ at 24 months, confirming the peculiar effects on glomerular hemodynamics of the latest generation of dihydropyridines.

In conclusion, even if there is sound scientific evidence suggesting the efficacy of ACE inhibitors plus CCBs in reducing proteinuria, the individual role of the two drug classes is still a matter of debate; at least in the case of older dihydropyridines, most of the antiproteinuric effects could be explained by ACE inhibition alone and/or by the additional $\mathrm{BP}$ reduction obtained by combination therapy. In any case, 
combination therapy with ACE inhibitors and CCBs may reduce the slope of GFR reduction. ${ }^{114}$

\section{Other ACE inhibitor combinations ACE inhibitor plus angiotensin receptor blocker}

The RAS has evolved to play an integral role in the preservation of hemodynamic stability in human beings, by regulating extracellular fluid volume, sodium balance, and $\mathrm{CV}$ function through direct and indirect effects on multiple organ systems. ${ }^{136}$ Activation of the renin-angiotensin axis produces the biologically active peptide angiotensin II, which has several structural and hemodynamic effects, including stimulation of the sympathetic nervous system, vasoconstriction, increased aldosterone release and sodium retention, cardiac remodeling, smooth muscle cells growth and proliferation, vascular inflammation, generation of reactive oxygen species, endothelial dysfunction, renal fibrosis and so forth. ACE inhibitors and ARBs work at different steps of the RAS. Although ACE inhibitors are able to reduce angiotensin II formation, non-ACE dependent pathways have also been identified. ${ }^{137}$ On the other hand, ARBs antagonize the binding of angiotensin II to the $\mathrm{AT}_{1}$ receptor, which mediates most of the undesirable effects associated with angiotensin II. Each of these drug classes has been shown to be effective in the treatment of congestive heart failure, proteinuric chronic kidney disease (diabetic or not) and high-CV risk patients. For example, the RESOLVD pilot study ${ }^{138}$ demonstrated that combining enalapril with candesartan provides superior suppression of left-ventricular remodeling and RAS neurohormones as opposed to either therapy alone. The individual success of ACE inhibitors and ARBs has fueled the theory that combination therapy should provide additional $\mathrm{CV}$ and renal protection. The foundation of this premise, although biologically plausible, has yet to be proven in a compelling enough fashion to support the everyday use of these two drug classes in combination. To date, no long-term clinical trials have assessed mortality and morbidity with ACE inhibitor/ ARB combination therapy in a population consisting exclusively of type 2 diabetic hypertensives. In the VALsartan In Acute myocardial iNfarcTion trial, ${ }^{139} 14,703$ patients $(55.3 \%$ hypertensives) with acute MI complicated by heart failure or left ventricular systolic dysfunction or both were randomized to captopril $(n=4909)$, valsartan $(n=4909)$ or combination therapy $(\mathrm{n}=4885)$. In the latter arm, there were $1146(23.5 \%)$ diabetic patients (mostly type 2 diabetics, over $70 \%$ hypertensives). ${ }^{140}$ In these subjects, the combination regimen did not reduce total mortality $(\mathrm{p}=0.7)$ or the combined $\mathrm{CV}$ endpoint $(\mathrm{p}=0.85)$, as compared with captopril monotherapy, despite additional lowering of BP and a clear increase in the rate of intolerance to treatment. The Ongoing Telmisartan Alone and in Combination with Ramipril Global Endpoint Trial (ONTARGET) $)^{141}$ enrolled 25620 patients at high CV risk, randomized to ramipril $(\mathrm{n}=8576)$, telmisartan $(\mathrm{n}=8542)$ or both $(\mathrm{n}=8502) .3220$ diabetic patients (mostly type 2 diabetics with hypertension) received the combination of the two drugs. Again, combination therapy did not offer an additional reduction in the primary outcome (death from CV causes, MI, stroke, or hospitalization for heart failure; $\mathrm{p}=0.15$ ), compared with ramipril, but significantly increased the risk of hypotension, syncope, hyperkalemia and renal dysfunction. Similarly, no benefit of combination therapy on the primary renal outcome (dialysis, doubling of serum creatinine, and death) was seen in participants with diabetic nephropathy; ${ }^{142}$ in the ONTARGET trial, the only benefit provided by dual RAS blockade was a greater reduction in urinary albumin excretion. This finding is consistent with a recent meta-analysis investigating combination therapy with ACE inhibitors and ARBs for diabetic nephropathy ${ }^{143}$, wherein the combination regimen lowered 24-hour proteinuria to a greater extent than either drug as monotherapy, even if the few long-term studies included (12 months $)^{144,145}$ had not demonstrated any benefit.

As a consequence, concerns about dual-agent blockade of the RAS have been raised, particularly about the potential increase in the incidence of hyperkalemia and decrease in the GFR, even in the presence of normal renal arteries (late-onset renal failure from angiotensin blockade, LORFFAB). ${ }^{146,147}$

\section{ACE inhibitor plus aliskiren}

Aliskiren is a low-molecular-weight hydrophilic non-peptide, which exerts a potent and specific competitive inhibition on renin, the initial and rate-limiting step of the RAS, reducing angiotensin I generation from angiotensinogen. ${ }^{148}$ A reactive increase in the activity of the renin occurs when either ACE inhibitors or ARBs are used for long periods. Renin exerts additional actions through a renin receptor, leading to the production of angiotensin and aldosterone. Therefore, the prospect of dual blockade of the RAS with aliskiren and an ACE inhibitor has appeared promising. A phase 3 clinical trial randomized 837 patients with diabetes (mostly type 2 diabetics) and hypertension to aliskiren $150 \mathrm{mg} /$ day alone, ramipril $5 \mathrm{mg}$ /day alone or a combination of aliskiren $150 \mathrm{mg} /$ day and ramipril $5 \mathrm{mg} /$ day. ${ }^{149}$ After 4 weeks, the 
dose in each arm was doubled for an additional 4 weeks. At 8 weeks, combination therapy was significantly more effective in reducing mean sitting SBP compared with either monotherapy $(\mathrm{p}<0.005)$, with an additional BP reduction of 4.6/2.1 mmHg over ramipril monotherapy. Treatments were well tolerated, with adverse events occurring in $33.8 \%, 32.3 \%$ and $30 \%$ of patients on ramipril, aliskiren, or aliskiren/ramipril, respectively. Most adverse events were mild or moderate. A substudy in 173 patients who underwent 24-hour BP monitoring at baseline and at the end of the trial $^{150}$ showed that adding aliskiren to ramipril improves 24-hour BP control compared with monotherapy in patients with diabetes and hypertension, with a greater reduction in the early morning BP surge (21-24 hours post dose), which is associated with an increased $\mathrm{CV}$ risk.

\section{ACE inhibitor plus $\alpha$-adrenergic blocker}

In a small crossover trial, ${ }^{151} 76$ patients with type 2 diabetes, hypertension and albuminuria were randomized to receive the ACE inhibitor cilazapril (2.5-10 mg/day), the $\alpha$-adrenergic blocker doxazosin (2-8 mg/day) or both drugs at half doses. Patients of the first two groups received a single agent for 4 months, the drugs were then crossed for an additional 4 months followed by the addition of HCTZ for a final 4-month period. Patients of the cilazapril/doxazosin group received both drugs for 4 months, then HCTZ was added for an additional 4 months. All three initial regimens resulted in significant decline in both SBP and DBP values $(\mathrm{p}<0.001)$. The combination of cilazapril with doxazosin had a significant greater antialbuminuric effect: albuminuria decreased from $365 \pm 115$ to $162 \pm 105 \mathrm{mg} / 24$ hours, an RR of $56 \%(95 \%$ CI 16\%-88\%; p = 0.001), as compared with $350 \pm 105$ down to $205 \pm 96 \mathrm{mg} / 24$ hours in the cilazapril group and with $373 \pm 121$ down to $322 \pm 107$ $\mathrm{mg} / 24$ hours in the doxazosin group. In the combination arm, the addition of HCTZ was followed by a further decline in albuminuria.

\section{Which is the "best" ACE inhibitor combination in hypertensive patients with type 2 diabetes? Update after the GUARD and ACCOMPLISH trials}

Two recently published trials, GUARD and ACCOMPLISH, may help to shed a new light on this area. They are the first clinical studies specifically designed to directly compare initial combination therapy of either ACE inhibitor and diuretic or ACE inhibitor and CCB. In the Gauging Albuminuria Reduction with Lotrel in Diabetic Patients with Hypertension (GUARD) trial, ${ }^{114} 332$ hypertensive, albuminuric type 2 diabetics were assigned to benazepril/amlodipine or benazepril/HCTZ. After 1 year of treatment, both combinations significantly reduced the urinary albumin to creatinine ratio and the sitting $\mathrm{BP}$. However, while $\mathrm{BP}$ was reduced more by the combination $\mathrm{ACE}$ inhibitor/CCB, initial treatment with benazepril and $\mathrm{HCTZ}$ resulted in a greater reduction in albuminuria, compared with benazepril plus amlodipine. The reasons for this difference could be multiple. First, conventional dihydropyridinic CCBs, such as amlodipine, may cause vasodilation of afferent renal arterioles with minor changes in the efferent arteriole diameter, with a consequent increase in intraglomerular pressure and proteinuria. Therefore, the observations of the GUARD cannot be extended to other dihydropyridinic (ie, manidipine) or non-dihydropyridinic CCBs, as clearly showed by the recently published AMANDHA trial. ${ }^{135}$ Other possible explanations suggested by the authors of the trial include greater reduction in eGFR in the diuretic group as well as differences in preexisting volume status. Finally, high sodium intake may blunt the antiproteinuric effects of ACE inhibitors; in such patients, the use of thiazide diuretics may overcome this blunting effect. However, another recently published trial in hypertensive patients with type 2 diabetes ${ }^{152}$ showed that adding manidipine on top of RAS blocker, candesartan, reduced the urinary albumin excretion by $53 \%$, while thiazide diuretic add-on was ineffective. Altough obtained with a combination therapy based on an angiotensin receptor blocker instead of an ACE inhibitor, these results are in sharp contrast with the discussed GUARD trial.

Interestingly, rates of progression to overt diabetic nephropathy by the end of the GUARD trial were similar between the benazepril/amlodipine and the benazepril/ hydrochlorotiazide group ( $4.6 \%$ vs $4.0 \%, \mathrm{p}=0.79)$. More importantly, the mean decrease in the estimated GFR (eGFR) over the 52-week period was less in the benazepril/amlodipine group than in the benazepril/HCTZ group $(-2.03 \pm 14.2$ vs $-13.64 \pm 16.1 \mathrm{~mL} / \mathrm{min}, \mathrm{p}<0.0001)$. Again, a greater reduction in proteinuria, as observed in the benazepril/HCTZ arm of GUARD, does not necessarily translate into greater renoprotection, as expressed by the slope of GFR reduction.

Further in favor of the ACE inhibitor/CCB combination, the recently published ACCOMPLISH trial ${ }^{132}$ demonstrated a striking superiority of the benazepril/amlodipine combination, as compared with benazepril/HCTZ, in reducing CV events in 11,506 hypertensive patients at high $\mathrm{CV}$ risk, $60 \%$ of 
whom were diabetics. After a mean of 30 months of treatment exposure, the primary outcome, which was defined as the composite of a CV event and death from $\mathrm{CV}$ causes, occurred in 552 patients $(9.6 \%)$ in the benazepril/amlodipine group as compared with 679 patients $(11.8 \%)$ in the benazepril/HCTZ group (HR 0.80, p < 0.001). For the secondary endpoint of death from $\mathrm{CV}$ causes plus nonfatal $\mathrm{MI}$ and non-fatal stroke, there were 288 events (5\%) in the first group as compared with $364(6.3 \%)$ in the second group (HR 0.79, p = 0.002); similarly, for the secondary endpoint of $\mathrm{CV}$ events, there were 494 events $(8.6 \%)$ in the benazepril/amlodipine arm versus $592(10.3 \%)$ in the benazepril/HCTZ arm (HR 0.83, $\mathrm{p}=0.002)$.

In conclusion, emerging evidence strongly supports the use of an ACE inhibitor/CCB combination in high-risk patients. Because more than $75 \%$ of hypertensive patients with type 2 diabetes will require a combination therapy to adequately control BP, ${ }^{17,153}$ an ACE inhibitor/CCB association may be the first choice for controlling BP in hypertensive patients with type 2 diabetes, providing at the same time both reno- and cardioprotection.

\section{Disclosures}

The authors disclose no conflicts of interest.

\section{References}

1. Steinbrook R. Facing the Diabetes Epidemic - Mandatory Reporting of Glycosylated Hemoglobin Values in New York City. N Engl J Med. 2006;354(6):545-548.

2. Wild S, Roglic G, Green A, Sicree R, King H. Global prevalence of diabetes: estimates for the year 2000 and projections for 2030. Diabetes Care. 2004;27(5):1047-1053.

3. Stults B, Jones RE. Management of Hypertension in Diabetes. Diabetes Spectr. 2006;19(1):25-31.

4. DeFronzo RA, Ferrannini E. Insulin resistance. A multifaceted syndrome responsible for NIDDM, obesity, hypertension, dyslipidemia, and atherosclerotic cardiovascular disease. Diabetes Care. 1991;14(3):173-194.

5. Garg JP, Bakris GL. Microalbuminuria: marker of vascular dysfunction, risk factor for cardiovascular disease. Vasc Med. 2002;7(1):35-43.

6. Mancia G, De Backer G, Dominiczak A, et al. Guidelines for the Management of Arterial Hypertension: The Task Force for the Management of Arterial Hypertension of the European Society of Hypertension (ESH) and of the European Society of Cardiology (ESC). J Hypertens. 2007;25(6):1105-1187.

7. Beckman JA, Creager MA, Libby P. Diabetes and atherosclerosis: epidemiology, pathophysiology, and management. JAMA. 2002; 287(19):2570-2581.

8. Sowers JR, Epstein M, Frohlich ED. Diabetes, hypertension, and cardiovascular disease: an update. Hypertension. 2001;37(4):1053-1059.

9. Rosamond W, Flegal K, Friday G, et al. Heart disease and stroke statistics - 2007 update: a report from the American Heart Association Statistics Committee and Stroke Statistics Subcommittee. Circulation. 2007;115(5):e69-e171.

10. Movahed MR, Hashemzadeh M, Jamal MM. Diabetes mellitus is a strong, independent risk for atrial fibrillation and flutter in addition to other cardiovascular disease. Int J Cardiol. 2005;105(3):315-318.
11. Tomson C, Ford D, Ansell D. The UK Renal Registry: an overview. Br J Hosp Med (Lond). 2008;69(10):548-549.

12. MMWR WR. Racial differences in trends of end-stage renal disease, by primary diagnosis - United States, 1994-2004. MMWR Morb Mortal Wkly Rep. 2007;56(11):253-256.

13. Thomas MC, Atkins RC. Blood pressure lowering for the prevention and treatment of diabetic kidney disease. Drugs. 2006;66(17):2213-2234.

14. Fong DS, Aiello LP, Ferris FL, 3rd Klein R. Diabetic retinopathy. Diabetes Care. 2004;27(10):2540-2553.

15. Tesfaye S, Chaturvedi N, Eaton SE, et al. Vascular risk factors and diabetic neuropathy. $N$ Engl J Med. 2005;352(4):341-350.

16. MacMahon S, Peto R, Cutler J, et al. Blood pressure, stroke, and coronary heart disease. Part 1, Prolonged differences in blood pressure: prospective observational studies corrected for the regression dilution bias. Lancet. 1990;335(8692):765-774.

17. Chobanian AV, Bakris GL, Black HR, et al. Seventh report of the Joint National Committee on Prevention, Detection, Evaluation, and Treatment of High Blood Pressure. Hypertension. 2003;42(6):1206-1252.

18. American Diabetes Association SG. Standards of medical care in diabetes - 2008. Diabetes Care. 2008;31 Supp1 1:S12-S54.

19. UKPDS SG. Tight blood pressure control and risk of macrovascular and microvascular complications in type 2 diabetes: UKPDS 38. UK Prospective Diabetes Study Group. BMJ. 1998;317(7160):703-713.

20. Prisant LM, Weir MR, Papademetriou V, et al. Low-dose drug combination therapy: an alternative first-line approach to hypertension treatment. Am Heart J. 1995;130(2):359-366.

21. Law MR, Wald NJ, Morris JK, Jordan RE. Value of low dose combination treatment with blood pressure lowering drugs: analysis of 354 randomised trials. BMJ 2003;326(7404):1427.

22. Lacourciere Y, Poirier L, Hebert D, et al. Antihypertensive efficacy and tolerability of two fixed-dose combinations of valsartan and hydrochlorothiazide compared with valsartan monotherapy in patients with stage 2 or 3 systolic hypertension: an 8-week, randomized, double-blind, parallel-group trial. Clin Ther. 2005;27(7):1013-1021.

23. Taylor AA. Combination drug treatment of hypertension: have we come full circle? Curr Cardiol Rep. 2004;6(6):421-426.

24. Epstein M, Bakris G. Newer approaches to antihypertensive therapy. Use of fixed-dose combination therapy. Arch Intern Med. 1996;156(17): 1969-1978.

25. Frank J. Managing hypertension using combination therapy. Am Fam Physician. 2008;77(9):1279-1286.

26. Williams B, Shaw A, Durrant R, Crinson I, Pagliari C, de Lusignan S. Patient perspectives on multiple medications versus combined pills: a qualitative study. QJM. 2005;98(12):885-893.

27. HOPE and micro-HOPE, SG. Effects of ramipril on cardiovascular and microvascular outcomes in people with diabetes mellitus: results of the HOPE study and MICRO-HOPE substudy. Heart Outcomes Prevention Evaluation Study Investigators. Lancet. 2000;355(9200): 253-259.

28. Niskanen L, Hedner T, Hansson L, Lanke J, Niklason A. Reduced cardiovascular morbidity and mortality in hypertensive diabetic patients on first-line therapy with an ACE inhibitor compared with a diuretic/ beta-blocker-based treatment regimen: a subanalysis of the Captopril Prevention Project. Diabetes Care. 2001;24(12):2091-2096.

29. Tatti P, Pahor M, Byington RP, et al. Outcome results of the Fosinopril Versus Amlodipine Cardiovascular Events Randomized Trial (FACET) in patients with hypertension and NIDDM. Diabetes Care. 1998;21(4):597-603.

30. Estacio RO, Jeffers BW, Hiatt WR, Biggerstaff SL, Gifford N, Schrier RW. The effect of nisoldipine as compared with enalapril on cardiovascular outcomes in patients with non-insulin-dependent diabetes and hypertension. N Engl J Med. 1998;338(10):645-652.

31. Turnbull F, Neal B, Algert C, et al. Effects of different blood pressurelowering regimens on major cardiovascular events in individuals with and without diabetes mellitus: results of prospectively designed overviews of randomized trials. Arch Intern Med. 2005;165(12): 1410-1419. 
32. Arauz-Pacheco C, Parrott MA, Raskin P. Hypertension management in adults with diabetes. Diabetes Care. 2004;27 Suppl 1:S65-S67.

33. Viberti G, Wheeldon NM. Microalbuminuria reduction with valsartan in patients with type 2 diabetes mellitus: a blood pressure-independent effect. Circulation. 2002;106(6):672-678.

34. Brenner BM, Cooper ME, de Zeeuw D, et al. Effects of losartan on renal and cardiovascular outcomes in patients with type 2 diabetes and nephropathy. N Engl J Med. 2001;345(12):861-869.

35. Lewis EJ, Hunsicker LG, Clarke WR, et al. Renoprotective effect of the angiotensin-receptor antagonist irbesartan in patients with nephropathy due to type 2 diabetes. N Engl J Med. 2001;345(12):851-860.

36. Parving HH, Lehnert H, Brochner-Mortensen J, Gomis R, Andersen S, Arner P. The effect of irbesartan on the development of diabetic nephropathy in patients with type 2 diabetes. N Engl J Med. 2001; 345(12):870-878.

37. Barnett A. Preventing renal complications in type 2 diabetes: results of the diabetics exposed to telmisartan and enalapril trial. $J$ Am Soc Nephrol. 2006;17(4 Suppl 2):S132-S135.

38. Palmer BF. Improving BP control with combined renin-angiotensin system blockade and thiazide diuretics in hypertensive patients with diabetes mellitus or kidney disease. Am J Cardiovasc Drugs. 2008; $8(1): 9-14$.

39. Whelton PK, Barzilay J, Cushman WC, et al. Clinical outcomes in antihypertensive treatment of type 2 diabetes, impaired fasting glucose concentration, and normoglycemia: Antihypertensive and LipidLowering Treatment to Prevent Heart Attack Trial (ALLHAT). Arch Intern Med. 2005;165(12):1401-1409.

40. Palmer BF. Renal dysfunction complicating the treatment of hypertension. N Engl J Med. 2002;347(16):1256-1261.

41. Kjeldsen SE, Os I, Hoieggen A, Beckey K, Gleim GW, Oparil S. Fixed-dose combinations in the management of hypertension: defining the place of angiotensin receptor antagonists and hydrochlorothiazide. Am J Cardiovasc Drugs. 2005;5(1):17-22.

42. Vaughan ED Jr, Carey RM, Peach MJ, Ackerly JA, Ayers CR. The renin response to diuretic therapyl A limitation of antihypertensive potential. Circ Res. 1978;42(3):376-381.

43. Greenberg A. Diuretic complications. Am J Med Sci. 2000;319(1):10-24.

44. Wilcox CS. Metabolic and adverse effects of diuretics. Semin Nephrol/ 1999;19(6):557-568.

45. Zillich AJ, Garg J, Basu S, Bakris GL, Carter BL. Thiazide diuretics, potassium, and the development of diabetes: a quantitative review. Hypertension. 2006;48(2):219-224.

46. Koster JC, Remedi MS, Masia R, Patton B, Tong A, Nichols CG. Expression of ATP-insensitive KATP channels in pancreatic beta-cells underlies a spectrum of diabetic phenotypes. Diabetes. 2006;55(11): 2957-2964.

47. Shafi T, Appel LJ, Miller ER 3rd, Klag MJ, Parekh RS. Changes in serum potassium mediate thiazide-induced diabetes. Hypertension. 2008;52(6):1022-1029.

48. Eriksson JW, Jansson PA, Carlberg B, et al. Hydrochlorothiazide, but not Candesartan, aggravates insulin resistance and causes visceral and hepatic fat accumulation: the mechanisms for the diabetes preventing effect of Candesartan (MEDICA) Study. Hypertension. 2008;52(6):1030-1037.

49. Carter BL, Einhorn PT, Brands M, et al. Thiazide-induced dysglycemia: call for research from a working group from the national heart, lung, and blood institute. Hypertension. 2008;52(1):30-36.

50. Asmar RG, London GM, O'Rourke ME, Safar ME. Improvement in blood pressure, arterial stiffness and wave reflections with a very-lowdose perindopril/indapamide combination in hypertensive patient: a comparison with atenolol. Hypertension. 2001;38(4):922-926.

51. Chanudet X, De Champvallins M. Antihypertensive efficacy and tolerability of low-dose perindopril/indapamide combination compared with losartan in the treatment of essential hypertension. Int J Clin Pract. 2001;55(4):233-239.

52. Corea L, Bentivoglio M, Verdecchia P. Low-dose captopril therapy in mild and moderate hypertension. Randomized comparison of twice daily vs three times daily doses. Hypertension. 1983;5(5Pt 2):III157-159.
53. Vidt DG. A controlled multiclinic study to compare the antihypertensive effects of MK-421, hydrochlorothiazide, and MK-421 combined with hydrochlorothiazide in patients with mild to moderate essential hypertension. J Hypertens Suppl. 1984;2(2):S81-S88.

54. Esnault VL, Ekhlas A, Delcroix C, Moutel MG, Nguyen JM. Diuretic and enhanced sodium restriction results in improved antiproteinuric response to RAS blocking agents. $J$ Am Soc Nephrol. 2005;16(2): 474-481.

55. Buter H, Hemmelder MH, Navis G, de Jong PE, de Zeeuw D. The blunting of the antiproteinuric efficacy of ACE inhibition by high sodium intake can be restored by hydrochlorothiazide. Nephrol Dial Transplant. 1998;13(7):1682-1685.

56. Heeg JE, de Jong PE, van der Hem GK, de Zeeuw D. Efficacy and variability of the antiproteinuric effect of ACE inhibition by lisinopril. Kidney Int. 1989;36(2):272-279.

57. Jones-Burton C, Mishra SI, Fink JC, et al. An in-depth review of the evidence linking dietary salt intake and progression of chronic kidney disease. Am J Nephrol. 2006;26(3):268-275.

58. Weinberger MH. Blood pressure and metabolic responses to hydrochlorothiazide, captopril, and the combination in black and white mild-to-moderate hypertensive patients. J Cardiovasc Pharmacol. 1985; 7 Suppl 1:S52-S55.

59. Opie L. Angiotensin-converting enzyme inhibitors: the advance continues. Third Edition, University of Cape Town Press. Chapter 3, 1999. p. 64-67. Chapter 10, p. 222-224.

60. Jauch KW, Hartl W, Guenther B, Wicklmayr M, Rett K, Dietze G. Captopril enhances insulin responsiveness of forearm muscle tissue in non-insulin-dependent diabetes mellitus. Eur J Clin Invest. 1987;17(5):448-454.

61. Kodama J, Katayama S, Tanaka K, Itabashi A, Kawazu S, Ishii J. Effect of captopril on glucose concentration. Possible role of augmented postprandial forearm blood flow. Diabetes Care. 1990;13(11): 1109-1111.

62. Jacob S, Warth B, Thies R, Gross A, Augustin HJ, Dietze GJ. Acute effects of various doses of captopril on glucose metabolism in humans. Third International Simposium on ACE inhibition, Amsterdam, The Netherlands. 1993.

63. Henriksen EJ, Jacob S. Angiotensin converting enzyme inhibitors and modulation of skeletal muscle insulin resistance. Diabetes Obes Metab. 2003;5(4):214-222.

64. Pollare T, Lithell H, Berne CA. Comparison of the effects of hydrochlorothiazide and captopril on glucose and lipid metabolism in patients with hypertension. $N$ Engl J Med. 1989;321(13): 868-873.

65. Vuorinen-Markkola H, Yki-Jarvinen H. Antihypertensive therapy with enalapril improves glucose storage and insulin sensitivity in hypertensive patients with non-insulin-dependent diabetes mellitus. Metabolism. 1995;44(1):85-89.

66. HOPE SG. Effects of ramipril on cardiovascular and microvascular outcomes in people with diabetes mellitus: results of the HOPE study and MICRO-HOPE substudy. Heart Outcomes Prevention Evaluation Study Investigators. Lancet. 2000;355(9200):253-259.

67. ALLHAT SG. Major outcomes in high-risk hypertensive patients randomized to angiotensin-converting enzyme inhibitor or calcium channel blocker vs diuretic: The Antihypertensive and LipidLowering Treatment to Prevent Heart Attack Trial (ALLHAT). JAMA. 2002;288(23):2981-2997.

68. Elliott WJ, Meyer PM. Incident diabetes in clinical trials of antihypertensive drugs: a network meta-analysis. Lancet. 2007;369(9557): 201-207.

69. Weinberger MH. Influence of an angiotensin converting-enzyme inhibitor on diuretic-induced metabolic effects in hypertension. Hypertension. 1983;5(5Pt 2):III132-138.

70. Shamiss A, Carroll J, Peleg E, Grossman E, Rosenthal T. The effect of enalapril with and without hydrochlorothiazide on insulin sensitivity and other metabolic abnormalities of hypertensive patients with NIDDM. Am J Hypertens. 1995;8(3):276-281. 
71. Parati G, omboni S, Malacco E. Antihypertensive efficacy of zofenopril and hydrochlorothiazide and their different combinations assessed by $24 \mathrm{~h}$ ambulatory blood pressure monitoring. Journal of Hypertension Supplement 2. 2005;S309.

72. Hunter SJ, Wiggam MI, Ennis CN, et al. Comparison of effects of captopril used either alone or in combination with a thiazide diuretic on insulin action in hypertensive Type 2 diabetic patients: a double-blind crossover study. Diabet Med. 1999;16(6):482-487.

73. McLaughlin DM, Atkinson AB, Ennis CN, et al. Comparison of effects of combined ACE inhibitor and low-dose thiazide diuretic with ACE inhibitor alone on insulin action in patients with hypertension and Type 2 diabetes: a double-blind crossover study. Diabet Med 2008;25(5):631-634.

74. Patel A, MacMahon S, Chalmers J, et al. Effects of a fixed combination of perindopril and indapamide on macrovascular and microvascular outcomes in patients with type 2 diabetes mellitus (the ADVANCE trial): a randomised controlled trial. Lancet. 2007;370(9590): 829-840.

75. Mogensen CE, Viberti G, Halimi S, et al. Effect of Low-Dose Perindopril/Indapamide on Albuminuria in Diabetes: Preterax in Albuminuria Regression: PREMIER. Hypertension. 2003;41(5): 1063-1071.

76. PROGRESS SG. Effects of a perindopril-based blood pressure lowering regimen on cardiac outcomes among patients with cerebrovascular disease. Eur Heart J. 2003;24(5):475-484.

77. Berthet K, Neal BC, Chalmers JP, et al. Reductions in the risks of recurrent stroke in patients with and without diabetes: The PROGRESS Trial. Blood Pressure. 2004;13(1):7-13.

78. Chan JC, Cockram CS, Nicholls MG, Cheung CK, Swaminathan R. Comparison of enalapril and nifedipine in treating non-insulin dependent diabetes associated with hypertension: one year analysis. BMJ. 1992;305(6860):981-985.

79. Patel A, MacMahon S, Chalmers J, et al. Intensive blood glucose control and vascular outcomes in patients with type 2 diabetes. $N$ Engl J Med. 2008;358(24):2560-2572.

80. Hansson L, Lindholm LH, Ekbom T, et al. Randomised trial of old and new antihypertensive drugs in elderly patients: cardiovascular mortality and morbidity the Swedish Trial in Old Patients with Hypertension-2 study. Lancet. 1999;354(9192):1751-1756.

81. Nosadini R, Tonolo G. Cardiovascular and renal protection in type 2 diabetes mellitus: the role of calcium channel blockers. J Am Soc Nephrol. 2002;13 Supp1 3:S216-S223.

82. Opie LH. Calcium channel blockers in hypertension: reappraisal after new trials and major meta-analyses. Am J Hypertens. 2001;14(10): 1074-1081.

83. Avanzini F, Tognoni G. INSIGHT and NORDIL. International Nifedipine GITS study: Intervention as a Goal in Hypertension Treatment. Nordic Diltiazem Study. Lancet. 2000;356(9245):1927-8; author reply 1928-1929.

84. Pitt B, Byington RP, Furberg CD, et al. Effect of amlodipine on the progression of atherosclerosis and the occurrence of clinical events. PREVENT Investigators. Circulation. 2000;102(13):1503-1510.

85. Zanchetti A, Rosei EA, Dal Palu C, Leonetti G, Magnani B, Pessina A. The Verapamil in Hypertension and Atherosclerosis Study (VHAS): results of long-term randomized treatment with either verapamil or chlorthalidone on carotid intima-media thickness. J Hypertens. 1998;16(11):1667-1676.

86. Folts JD, Schafer AI, Loscalzo J, Willerson JT, Muller JE. A perspective on the potential problems with aspirin as an antithrombotic agent: a comparison of studies in an animal model with clinical trials. $\mathrm{J} \mathrm{Am}$ Coll Cardiol. 1999;33(2):295-303.

87. Pumphrey CW, Fuster V, Dewanjee MK, Chesebro JH, Vlietstra RE, Kaye MP. Comparison of the antithrombotic action of calcium antagonist drugs with dipyridamole in dogs. Am J Cardiol. 1983;51(3): 591-595.

88. Fogari R. Ankle oedema and sympathetic activation. Drugs. 2005; 65 Suppl 2:21-27.
89. Fogari R, Zoppi A, Corradi L, Preti P, Malalamani GD, Mugellini A. Effects of different dihydropyridine calcium antagonists on plasma norepinephrine in essential hypertension. J Hypertens. 2000;18(12): 1871-1875.

90. Smith AC, Toto R, Bakris GL. Differential effects of calcium channel blockers on size selectivity of proteinuria in diabetic glomerulopathy. Kidney Int. 1998;54(3):889-896.

91. Hayashi K, Nagahama T, Oka K, Epstein M, Saruta T. Disparate effects of calcium antagonists on renal microcirculation. Hypertens Res. 1996;19(1):31-36.

92. Hayashi K, Ozawa Y, Fujiwara K, Wakino S, Kumagai H, Saruta T. Role of actions of calcium antagonists on efferent arterioles - with special references to glomerular hypertension. Am J Nephrol. 2003;23(4): 229-244.

93. Hayashi K, Wakino S, Sugano N, Ozawa Y, Homma K, Saruta T. Ca ${ }^{2+}$ channel subtypes and pharmacology in the kidney. Circ Res. 2007; 100(3):342-353.

94. Harris D, Thomas M, Johnson D, Nicholls K, Gillin A. The CARI guidelines. Prevention of progression of kidney disease. Nephrology (Carlton). 2006;11 Suppl 1:S2-197.

95. Brouwer RM, Bolli P, Erne P, Conen D, Kiowski W, Buhler FR. Antihypertensive treatment using calcium antagonists in combination with captopril rather than diuretics. J Cardiovasc Pharmacol. 1985; 7 Suppl 1:S88-S91.

96. Chrysant SG, Bakris GL. Amlodipine/benazepril combination therapy for hypertensive patients nonresponsive to benazepril monotherapy. Am J Hypertens. 2004;17(7):590-596.

97. Cushman WC, Cohen JD, Jones RP, Marbury TC, Rhoades RB, Smith LK. Comparison of the fixed combination of enalapril/diltiazem ER and their monotherapies in stage 1 to 3 essential hypertension. Am J Hypertens. 1998;11(1Pt 1):23-30.

98. Fitscha P, Meisner W, Hitzenberger G. Evaluation of isradipine and captopril alone or in combination for the treatment of hypertension. J Cardiovasc Pharmacol. 1991;18 Suppl 3:S12-S14.

99. Jamerson KA, Nwose O, Jean-Louis L, Schofield L, Purkayastha D, Baron M. Initial angiotensin-converting enzyme inhibitor/calcium channel blocker combination therapy achieves superior blood pressure control compared with calcium channel blocker monotherapy in patients with stage 2 hypertension. Am J Hypertens. 2004;17(6): 495-501.

100. Mancia G, Omboni S, Grassi G. Combination treatment in hypertension: the VeraTran Study. Am J Hypertens. 1997;10(7Pt 2): 153S-158S.

101. Neutel JM, Smith DH, Weber MA, Schofield L, Purkayastha D, Gatlin M. Efficacy of combination therapy for systolic blood pressure in patients with severe systolic hypertension: the Systolic Evaluation of Lotrel Efficacy and Comparative Therapies (SELECT) study. J Clin Hypertens (Greenwich). 2005;7(11):641-646; quiz 647-648

102. Philipp T, Smith TR, Glazer R, et al. Two multicenter, 8-week, randomized, double-blind, placebo-controlled, parallel-group studies evaluating the efficacy and tolerability of amlodipine and valsartan in combination and as monotherapy in adult patients with mild to moderate essential hypertension. Clin Ther. 2007;29(4):563-580.

103. Tedesco MA, Natale F, Calabro R. Effects of monotherapy and combination therapy on blood pressure control and target organ damage: a randomized prospective intervention study in a large population of hypertensive patients. J Clin Hypertens (Greenwich). 2006;8(9):634-641.

104. Ferrier C, Ferrari P, Weidmann P, Keller U, Beretta-Piccoli C, Riesen WF. Antihypertensive therapy with $\mathrm{Ca}^{2+}$. Antagonist verapamil and/or ACE inhibitor enalapril in NIDDM patients. Diabetes Care. 1991;14(10):911-914.

105. Bakris G, Molitch M, Hewkin A, et al. Differences in glucose tolerance between fixed-dose antihypertensive drug combinations in people with metabolic syndrome. Diabetes Care. 2006;29(12): 2592-2597. 
106. Dahlof B, Sever PS, Poulter NR, et al. Prevention of cardiovascular events with an antihypertensive regimen of amlodipine adding perindopril as required versus atenolol adding bendroflumethiazide as required, in the Anglo-Scandinavian Cardiac Outcomes Trial-Blood Pressure Lowering Arm (ASCOT-BPLA): a multicentre randomised controlled trial. Lancet. 2005;366(9489):895-906.

107. Rubio-Guerra AF, Arceo-Navarro A, Vargas-Ayala G, RodriguezLopez L, Lozano-Nuevo JJ, Gomez-Harper CT. The effect of trandolapril and its fixed-dose combination with verapamil on proteinuria in normotensive adults with type 2 diabetes. Diabetes Care. 2004;27(7):1688-1691.

108. Fogari R, Derosa G, Zoppi A, et al. Effect of delapril/manidipine vs olmesartan/ hydrochlorothiazide combination on insulin sensitivity and fibrinogen in obese hypertensive patients. Intern Med. 2008;47(5):361-366.

109. Baron AD, Brechtel G, Wallace P, Edelman SV. Rates and tissue sites of non-insulin- and insulin-mediated glucose uptake in humans. Am J Physiol. 1988;255(6 Pt 1):E769-E774.

110. Draznin B, Sussman KE, Eckel RH, Kao M, Yost T, Sherman NA. Possible role of cytosolic free calcium concentrations in mediating insulin resistance of obesity and hyperinsulinemia. J Clin Invest. 1988;82(6):1848-1852.

111. Cheng A, Frishman WH. Use of angiotensin-converting enzyme inhibitors as monotherapy and in combination with diuretics and calcium channel blockers. J Clin Pharmacol. 1998;38(6):477-491.

112. Frishman WH, Ram CV, McMahon FG, et al. Comparison of amlodipine and benazepril monotherapy to amlodipine plus benazepril in patients with systemic hypertension: a randomized, double-blind, placebo-controlled, parallel-group study. The Benazepril/Amlodipine Study Group. J Clin Pharmacol. 1995;35(11):1060-1066.

113. Kaplan NM. Implications for cost-effectiveness. Combination therapy for systemic hypertension. Am J Cardiol. 1995;76(8):595-597.

114. Bakris GL, Toto RD, McCullough PA, Rocha R, Purkayastha D, Davis P. Effects of different ACE inhibitor combinations on albuminuria: results of the GUARD study. Kidney Int. 2008;73(11):1303-1309.

115. Mital S, Loke KE, Slater JP, Addonizio L, Gersony WM, Hintze TH. Synergy of amlodipine and angiotensin-converting enzyme inhibitors in regulating myocardial oxygen consumption in normal canine and failing human hearts. Am J Cardiol. 1999;83(12A):92H-98H.

116. Siragy HM, Xue C, Webb RL. Beneficial effects of combined benazepril-amlodipine on cardiac nitric oxide, cGMP, and TNFalpha production after cardiac ischemia. $J$ Cardiovasc Pharmacol. 2006;47(5):636-642.

117. Zhang X, Xu X, Nasjletti A, Hintze TH. Amlodipine enhances NO production induced by an ACE inhibitor through a kinin-mediated mechanism in canine coronary microvessels. J Cardiovasc Pharmacol. 2000;35(2): 195-202.

118. Weir MR. Targeting mechanisms of hypertensive vascular disease with dual calcium channel and renin-angiotensin system blockade. J Hum Hypertens. 2007;21(10):770-779.

119. Fogari R, Preti P, Lazzari P, et al. Effect of benazepril amlodipine combination on fibrinolysis in hypertensive diabetic patients. Eur $J$ Clin Pharmacol. 2003;59(4):271-275.

120. Neutel JM, Smith DH, Weber MA. Effect of antihypertensive monotherapy and combination therapy on arterial distensibility and left ventricular mass. Am J Hypertens. 2004;17(1):37-42.

121. Winer N, Folker A, Murphy JA, et al. Effect of fixed-dose ACE-inhibitor/calcium channel blocker combination therapy vs ACE-inhibitor monotherapy on arterial compliance in hypertensive patients with type 2 diabetes. Prev Cardiol. 2005;8(2):87-92.

122. Bakris GL, Weir MR. Achieving goal blood pressure in patients with type 2 diabetes: conventional versus fixed-dose combination approaches. J Clin Hypertens (Greenwich). 2003;5(3):202-209.

123. Agrawal R, Marx A, Haller H. Efficacy and safety of lercanidipine versus hydrochlorothiazide as add-on to enalapril in diabetic populations with uncontrolled hypertension. $J$ Hypertens. 2006;24(1): 185-192.
124. Tobe S, Kawecka-Jaszcz K, Zannad F, Vetrovec G, Patni R, Shi H. Amlodipine added to quinapril vs quinapril alone for the treatment of hypertension in diabetes: the Amlodipine in Diabetes (ANDI) trial. J Clin Hypertens (Greenwich). 2007;9(2):120-127.

125. Roca-Cusachs A, Schmieder RE, Triposkiadis F, et al. Efficacy of manidipine/delapril versus losartan/hydrochlorothiazide fixed combinations in patients with hypertension and diabetes. $J$ Hypertens. 2008;26(4):813-818.

126. Hansson L, Zanchetti A, Carruthers SG, et al. Effects of intensive blood-pressure lowering and low-dose aspirin in patients with hypertension: principal results of the Hypertension Optimal Treatment (HOT) randomised trial. HOT Study Group. Lancet. 1998;351(9118): $1755-1762$.

127. Tuomilehto J, Rastenyte D, Birkenhager WH, et al. Effects of calciumchannel blockade in older patients with diabetes and systolic hypertension. Systolic Hypertension in Europe Trial Investigators. $N$ Engl $J$ Med. 1999;340(9):677-684.

128. Pepine CJ, Handberg EM, Cooper-DeHoff RM, et al. A calcium antagonist vs a non-calcium antagonist hypertension treatment strategy for patients with coronary artery disease. The International VerapamilTrandolapril Study (INVEST): a randomized controlled trial. JAMA. 2003;290(21):2805-2816.

129. Bakris GL, Gaxiola E, Messerli FH, et al. Clinical Outcomes in the Diabetes Cohort of the International Verapamil SR-Trandolapril Study. Hypertension. 2004;44(5):637-642.

130. Ruggenenti P, Fassi A, Ilieva AP, et al. Preventing microalbuminuria in type 2 diabetes. N Engl J Med. 2004;351(19):1941-1951.

131. Ostergren J, Poulter NR, Sever PS, et al. The Anglo-Scandinavian Cardiac Outcomes Trial: blood pressure-lowering limb: effects in patients with type II diabetes. J Hypertens. 2008;26(11):2103-2111.

132. Jamerson K, Weber MA, Bakris GL, et al. Benazepril plus amlodipine or hydrochlorothiazide for hypertension in high-risk patients. $N$ Engl J Med. 2008;359(23):2417-2428.

133. Bakris GL, Weir MR, DeQuattro V, McMahon FG. Effects of an ACE inhibitor/calcium antagonist combination on proteinuria in diabetic nephropathy. Kidney Int. 1998;54(4):1283-1289.

134. Fogari R, Preti P, Zoppi A, et al. Effects of amlodipine fosinopril combination on microalbuminuria in hypertensive type 2 diabetic patients. Am J Hypertens. 2002;15(12):1042-1049.

135. Martinez-Martin FJ, Saiz-Satjes M. Add-on manidipine versus amlodipine in diabetic patients with hypertension and microalbuminuria: the AMANDHA study. Expert Rev Cardiovasc Ther. 2008;6(10): 1347-1355.

136. Perazella MA, Setaro JF. Renin-angiotensin-aldosterone system: fundamental aspects and clinical implications in renal and cardiovascular disorders. J Nucl Cardiol. 2003;10(2):184-196.

137. Schmieder RE, Hilgers KF, Schlaich MP, Schmidt BM. Reninangiotensin system and cardiovascular risk. Lancet. 2007;369(9568): 1208-1219.

138. McKelvie RS, Yusuf S, Pericak D, et al. Comparison of candesartan, enalapril, and their combination in congestive heart failure: randomized evaluation of strategies for left ventricular dysfunction (RESOLVD) pilot study. The RESOLVD Pilot Study Investigators. Circulation. 1999;100(10):1056-1064.

139. Pfeffer MA, McMurray JJ, Velazquez EJ, et al. Valsartan, captopril, or both in myocardial infarction complicated by heart failure, left ventricular dysfunction, or both. N Engl J Med. 2003;349(20):1893-1906.

140. Aguilar D, Solomon SD, Kober L, et al. Newly diagnosed and previously known diabetes mellitus and 1-year outcomes of acute myocardial infarction: the VALsartan In Acute myocardial iNfarcTion (VALIANT) trial. Circulation. 2004;110(12):1572-158.

141. Yusuf S, Teo KK, Pogue J, et al. Telmisartan, ramipril, or both in patients at high risk for vascular events. $N$ Engl J Med. 2008;358(15):1547-1559.

142. Mann JFE, Schmieder RE, McQueen M, et al. Renal outcomes with telmisartan, ramipril, or both, in people at high vascular risk (the ONTARGET study): a multicentre, randomised, double-blind, controlled trial. The Lancet. 2008;372(9638):547-553. 
143. Jennings DL, Kalus JS, Coleman CI, Manierski C, Yee J. Combination therapy with an ACE inhibitor and an angiotensin receptor blocker for diabetic nephropathy: a meta-analysis. Diabet Med. 2007;24(5): 486-493.

144. Andersen NH, Poulsen PL, Knudsen ST, et al. Long-term dual blockade with candesartan and lisinopril in hypertensive patients with diabetes: the CALM II study. Diabetes Care. 2005;28(2): 273-277.

145. Tutuncu NB, Gurlek A, Gedik O. Efficacy of ACE inhibitors and ATII receptor blockers in patients with microalbuminuria: a prospective study. Acta Diabetol. 2001;38(4):157-161.

146. Onuigbo M, Onuigbo N. Late-onset renal failure from angiotensin blockade (LORFFAB) in 100 CKD patients. International Urology and Nephrology. 2008;40(1):233-239.

147. Onuigbo MA. Reno-prevention vs. reno-protection: a critical reappraisal of the evidence-base from the large RAAS blockade trials after ontarget - a call for more circumspection. QJM. 2008.

148. Verdecchia P, Angeli F, Mazzotta G, Gentile G, Reboldi G. The renin angiotensin system in the development of cardiovascular disease: role of aliskiren in risk reduction. Vasc Health Risk Manag. 2008;4(5): 971-981.
149. Uresin Y, Taylor AA, Kilo C, et al. Efficacy and safety of the direct renin inhibitor aliskiren and ramipril alone or in combination in patients with diabetes and hypertension. Journal of Renin-AngiotensinAldosterone System. 2007;8(4):190-200.

150. Taylor A, Tschope D, Kilo C, Ibram G, Fang H, Satlin A. Adding aliskiren to ramipril improves 24-hour blood pressure control compared to ramipril alone in patients with diabetes and hypertension. J Hypertens. 2006;24(Suppl 4):S81. Abstract P4.268.

151. Rachmani R, Levi Z, Slavachevsky I, Half-Onn E, Ravid M. Effect of an alpha-adrenergic blocker, and ACE inhibitor and hydrochlorothiazide on blood pressure and on renal function in type 2 diabetic patients with hypertension and albuminuria. A randomized cross-over study. Nephron. 1998;80(2):175-182.

152. Fogari R, Corradi L, Zoppi A, et al. Addition of manidipine improves the antiproteinuric effect of candesartan in hypertensive patients with type II diabetes and microalbuminuria. Am J Hypertens. 2007 20(10):1092-1096.

153. Bakris GL, Williams M, Dworkin L, et al. Preserving renal function in adults with hypertension and diabetes: a consensus approach. National Kidney Foundation Hypertension and Diabetes Executive Committees Working Group. Am J Kidney Dis. 2000;36(3):646-661.
Vascular Health and Risk Management

\section{Publish your work in this journal}

Vascular Health and Risk Management is an international, peerreviewed journal of therapeutics and risk management, focusing on concise rapid reporting of clinical studies on the processes involved in the maintenance of vascular health; the monitoring, prevention and treatment of vascular disease and its sequelae; and the involvement of

\section{Dovepress}

metabolic disorders, particularly diabetes. This journal is indexed on PubMed Central and MedLine. The manuscript management system is completely online and includes a very quick and fair peer-review system, which is all easy to use. Visit http://www.dovepress.com/ testimonials.php to read real quotes from published authors. 